\title{
New Methods, Old Brains-A Systematic Review on the Effects of tDCS on the Cognition of Elderly People
}

\author{
Anna Siegert*, Lukas Diedrich and Andrea Antal \\ Department of Neurology, University Medical Center Göttingen, Göttingen, Germany
}

The world's population is aging. With this comes an increase in the prevalence of age-associated diseases, which amplifies the need for novel treatments to counteract cognitive decline in the elderly. One of the recently discussed non-pharmacological approaches is transcranial direct current stimulation (tDCS). TDCS delivers weak electric currents to the brain, thereby modulating cortical excitability and activity. Recent evidence suggests that tDCS, mainly with anodal currents, can be a powerful means to non-invasively enhance cognitive functions in elderly people with age-related cognitive decline. Here, we screened a recently developed tDCS database (http://tdcsdatabase.

OPEN ACCESS

Edited by: Masaki Sekino,

The University of Tokyo, Japan

Reviewed by:

Maxciel Zortea,

Hospital de Clínicas de Porto

Alegre, Brazil

Anirban Dutta,

University at Buffalo, United States

${ }^{*}$ Correspondence: Anna Siegert anna.siegert@stud.uni-goettingen.de

Specialty section: This article was submitted to Brain Imaging and Stimulation, a section of the journal

Frontiers in Human Neuroscience

Received: 24 June 2021 Accepted: 28 September 2021 Published: 27 October 2021

Citation:

Siegert A, Diedrich L and Antal A (2021) New Methods, Old Brains - A

Systematic Review on the Effects of

tDCS on the Cognition of Elderly

People.

Front. Hum. Neurosci. 15:730134 doi: 10.3389/fnhum.2021.730134 com) that is an open access source of published tDCS papers and reviewed 16 studies that applied tDCS to healthy older subjects or patients suffering from Alzheimer's Disease or pre-stages. Evaluating potential changes in cognitive abilities we focus on declarative and working memory. Aiming for more standardized protocols, repeated tDCS applications (2 mA, $30 \mathrm{~min}$ ) over the left dorso-lateral prefrontal cortex (LDLPFC) of elderly people seem to be one of the most efficient non-invasive brain stimulation (NIBS) approaches to slow progressive cognitive deterioration. However, inter-subject variability and brain state differences in health and disease restrict the possibility to generalize stimulation methodology and increase the necessity of personalized protocol adjustment by means of improved neuroimaging techniques and electrical field modeling.

Keywords: transcranial direct current stimulation (tDCS), cognition, episodic memory, declarative memory, aging, elderly

\section{INTRODUCTION}

The prognoses are alarming: by 2050 about $16 \%$ of the world's population will be aged over 65 (United Nations, 2019). With this comes a dramatic increase in the prevalence of age-related cognitive deterioration: in 30 years $\sim 152$ million people will be suffering from dementia, $60-70 \%$ of which with Alzheimer's Disease (AD) (World Health Organization, 2020). Although the body of research on neurodegenerative diseases is extensive, there is no intervention available to cure or to stop the progression of neurodegeneration and thus cognitive decline. This makes clear the necessity for novel treatment.

One of the recently discussed interventions among the novel treatment options is non-invasive brain stimulation (NIBS). The most common electrical stimulation method in the NIBS family used on humans is transcranial direct current stimulation (tDCS). Therefore, in this review we will focus on tDCS and its potential to interfere with age-related cognitive decline. 
During tDCS constant weak electric currents (usually 1$2 \mathrm{~mA}$ ) are applied to the cerebral cortex via external non-invasive electrodes to modulate neuronal excitability, firing rates and thus overall cortical activity (Priori et al., 1998; Nitsche and Paulus, 2000, 2001). Excitability changes are based on altered neuronal membrane potentials resulting in higher probabilities for de- or hyperpolarization (Purpura and McMurtry, 1965; Nitsche et al., 2003a; Lefaucheur et al., 2017). Depending on the direction of current flow (relative to orientations of neuronal axes) membrane potentials increase or decrease-with anodal tDCS being more likely to potentiate depolarization by increasing excitability, whereas cathodal tDCS tends to shift potentials toward hyperpolarization (Bindman et al., 1962; Purpura and McMurtry, 1965; Gorman, 1966; Nitsche and Paulus, 2000, 2001). However, these polarity-dependent predispositions cannot be generalized. Variations in several factors such as stimulation intensity (Batsikadze et al., 2013), duration (Nitsche et al., 2008; Batsikadze et al., 2013) or neuron orientation (more precisely somato-dendritic axis orientation) with respect to current flow (Kabakov et al., 2012; Rahman et al., 2013) may reverse excitatory into inhibitory effects and vice versa (Lefaucheur et al., 2017). Effects of tDCS have not only been observed online (during stimulation) but also offline (after stimulation) (Nitsche and Paulus, 2000, 2001; Nitsche et al., 2003c). Evidence from pharmacological studies suggests that tDCS impacts neuronal plasticity by modulating synaptic transmission via NMDA receptors (Liebetanz et al., 2002; Nitsche et al., 2003a, 2004) and GABA levels (Stagg et al., 2009). On a larger scale tDCS seems to affect functional network connectivity and the synchronization of neuronal populations across the cerebral cortex and within subcortical areas (Keeser et al., 2011; Polanía et al., 2011a,b, 2012).

In the past few years, based on the potential of tDCS to impact neuronal plasticity as well as network connectivity, tDCS studies have been extended to precisely investigate cognitive effects [for review see Shin et al. (2015)]. Evidence has been found that tDCS can modulate memory functions and enhance cognition in physiological (Berryhill and Jones, 2012; Hsu et al., 2015; Prehn and Flöel, 2015) as well as pathological aging (Flöel, 2014). Functional neuroplastic network modifications (Nitsche et al., 2003b) may compensate for age- and neurodegenerationrelated cognitive impairments. Further, on the molecular level, tDCS may modulate or induce synaptic plasticity, which potentially results in longer-lasting altered learning and memory capabilities as long-term potentiation (LTP) and -depression (LTD) are thought to be the physiological basis of learning and memory (Bear and Malenka, 1994; Baudry, 2001; Braunewell and Manahan-Vaughan, 2001). Consequently, applying tDCS in the context of age-related cognitive decline [for review see Coffman et al. (2014)] seems promising to restore memory and prevent further deterioration.

TDCS treatment approaches, mainly using anodal stimulation, that can interfere with cognitive decline in early disease-stages appear particularly promising to prevent or slow disease progression such as in mild cognitive impairment (MCI) (Petersen and Negash, 2008). However, since re-discovery of tDCS $\sim 20$ years ago, scientists have applied electrical stimulation in multiple fashions varying montage, current intensity and polarization, and duration as well as the context of application (Lefaucheur et al., 2017). Therefore, tDCS experiments have revealed promising albeit highly variable effects on cognition (Elder and Taylor, 2014). Reining in the high variance through method standardization would be a necessary next step toward developing efficient treatment approaches.

Here we review the potential of tDCS to modulate cognitive functions in the elderly using the tDCS database (http:// tdcsdatabase.com). The tDCS database is an open-access community-driven database that has been introduced to the scientific community by prestigious scientists of the field in 2018 (Grossman et al., 2018) and comprises 4.747 entries as of the writing of this review. It compiles mainly human tDCS studies that have been peer-reviewed and include all essential details on the application procedure as well as stimulation parameters (Grossman et al., 2018). Grossman et al. thereby aim to transparently provide scientists with all necessary information to develop efficient tDCS protocols and promote or improve clinical applications, facilitate meta-analysis across studies, and finally reduce variability of tDCS outcomes by optimizing experimental parameters based on previous evidence. For further details of inclusion criteria and maintenance of the database see Grossman et al. (2018).

We aimed to provide a comprehensive overview and further propose suitable tDCS procedures and parameters for future studies aiming to counteract cognitive age-associated deterioration. We focused on studies that investigated modulatory effects of tDCS to intervene with declarative and working memory deterioration as this is one of the major features of age-related cognitive decline (Rönnlund et al., 2005) and is accelerated in dementia (Reitz and Mayeux, 2014).

\section{METHODS}

\section{TDCS Database Research}

Literature database research was carried out in the tDCS database (http://tdcsdatabase.com) in February 2021. To ensure an efficient database screening several inclusion and exclusion criteria were determined. Inclusion criteria comprised: original paper on tDCS application(s) (previously unpublished data); subject age range starting $\geq 50$ years (studies with old and young subjects were included if the old subject's age range started $\geq 50$ years); focus on cognitive outcome measures of declarative or working memory and a double-blinded, randomized, and sham/placebo-controlled study design (unless it was a pilot or preliminary study). Aging is considered the strongest risk factor for MCI and AD. The prevalence of MCI is increasing dramatically wit age starting from $6.7 \%$ for individuals in the range of 60-64 years up to $25.2 \%$ for people in the range of $80-$ 84 years (Petersen et al., 2018). A similar situation applies for $\mathrm{AD}$ with the first symptoms usually occurring after the age of 60 years (Ballard et al., 2011). With our age range starting $\geq 50$ years we include all potential patients in early and later stages of disease. In this analysis we excluded reviews as well as metaanalyses, single-blinded or uncontrolled studies, case reports, and studies in which the blinding procedure was not mentioned or 


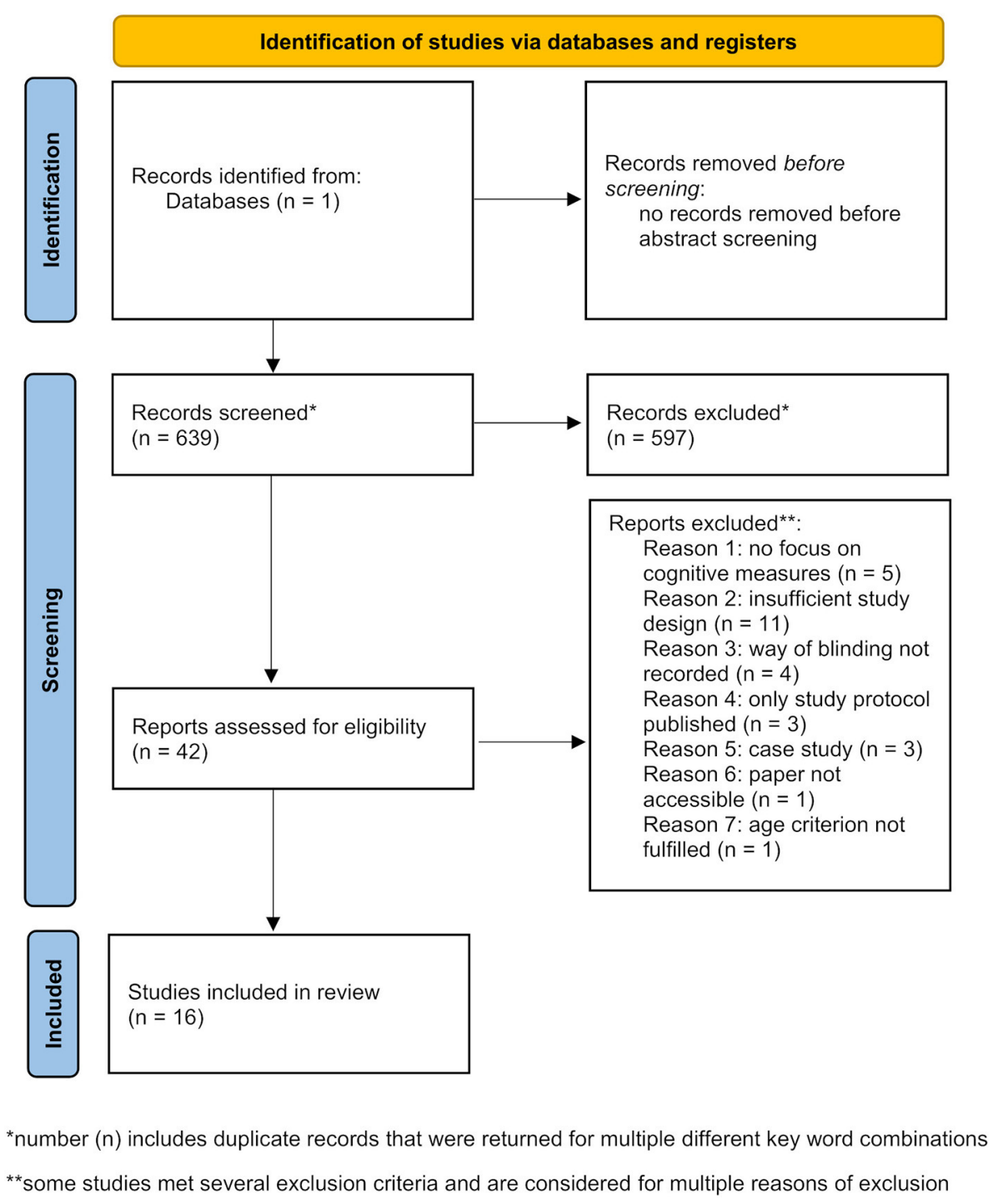

FIGURE 1 | PRISMA flow diagram depicting identification, screening, and inclusion strategies for the selection of the reviewed studies [modified from Page et al. (2021)].

insufficiently described so that it could not clearly be extracted whether double-blinding was assured. The whole process of study identification, screening, eligibility assessment and inclusion was summarized in a PRISMA flow diagram (Figure 1).

\section{Keyword Search}

Several keyword combinations were used to collect studies (that were further filtered according to above listed inclusion and exclusion criteria). Before precise filtering, abstracts were screened and all preliminary screening results were listed (Table 1). The following documentation of keyword search corresponds to the screening order whereby already included publications were not mentioned or listed again if repeatedly returned for other keyword combinations. To begin with, the keywords "transcranial direct current stimulation" or "tDCS" and "elderly" returned two studies that were directly excluded. Next, the search for "transcranial direct current stimulation" and "aging” revealed 186 studies. Abstract screening resulted in 12 studies considered relevant. Furthermore, "tDCS" and "aging" returned 24 additional studies of which two were selected. The keywords "transcranial direct current stimulation" or "tDCS" and "older" or "old" filtered out five studies of which 1 passed the abstract screening. Subsequently, the screening process was further specified. A combination of "transcranial direct current stimulation," "cognition" and "aging” returned 19 studies with 1 relevant publication. Keyword filtering for "transcranial direct current stimulation" or "tDCS," "memory" and "aging" added 1 more relevant publication out of 25 results, while "tDCS" and "memory" returned 34 studies of which five were considered relevant according to their abstracts. Another more focused 
TABLE 1 | List of all studies that passed the keyword and abstract screening in the tDCS database.

\begin{tabular}{|c|c|c|c|c|c|c|}
\hline Keywords (or other search key) & $\begin{array}{c}\# \\
\text { Studies }\end{array}$ & $\begin{array}{l}\text { Selected } \\
\text { studies } \\
\text { (PMID) }\end{array}$ & Title & References & Country & $\begin{array}{l}\text { Consideration } \\
\text { for review* }\end{array}$ \\
\hline \multirow[t]{12}{*}{$\begin{array}{l}\text { Transcranial direct current stimulation, } \\
\text { aging }\end{array}$} & 186 & 31196835 & $\begin{array}{l}\text { Effects of 6-month at-home transcranial direct current stimulation } \\
\text { on cognition and cerebral glucose metabolism in Alzheimer's } \\
\text { disease }\end{array}$ & Im et al., 2019 & South Korea & included \\
\hline & & 33160420 & $\begin{array}{l}\text { Cognitive training and brain stimulation in prodromal Alzheimer's } \\
\text { disease (AD-Stim)-study protocol for a double-blind randomized } \\
\text { controlled phase llb (monocenter) trial }\end{array}$ & Thams et al., 2020 & Germany & included \\
\hline & & 26923418 & $\begin{array}{l}\text { Older adults get episodic memory boosting from non-invasive } \\
\text { stimulation of prefrontal cortex during learning }\end{array}$ & Sandrini et al., 2016 & Italy & included \\
\hline & & 26200716 & $\begin{array}{l}\text { Better together: Left and right hemisphere engagement to reduce } \\
\text { age-related memory loss }\end{array}$ & Brambilla et al., 2015 & Italy & $\begin{array}{l}\text { excluded, (1) and } \\
\text { (2) }\end{array}$ \\
\hline & & 25449530 & $\begin{array}{l}\text { Transcranial direct current stimulation in mild cognitive impairment: } \\
\text { Behavioral effects and neural mechanisms }\end{array}$ & Meinzer et al., 2015 & Germany & included \\
\hline & & 29050849 & $\begin{array}{l}\text { Neuronal and behavioral effects of multi-day brain stimulation and } \\
\text { memory training }\end{array}$ & Antonenko et al., 2018 & Germany & excluded, (3) \\
\hline & & 28946572 & $\begin{array}{l}\text { Anodal transcranial direct current stimulation over the right } \\
\text { hemisphere improves auditory comprehension in a case of } \\
\text { dementia }\end{array}$ & Costa et al., 2017 & Italy & excluded, (5) \\
\hline & & 28707568 & $\begin{array}{l}\text { Effects of transcranial direct current stimulation on neural networks } \\
\text { in young and older adults }\end{array}$ & Martin et al., 2017 & Germany & $\begin{array}{l}\text { excluded, (1) and } \\
\text { (3) }\end{array}$ \\
\hline & & 28314813 & $\begin{array}{l}\text { tDCS-induced modulation of GABA levels and resting-state } \\
\text { functional connectivity in older adults }\end{array}$ & Antonenko et al., 2017 & Germany & excluded, (1) \\
\hline & & 27903289 & $\begin{array}{l}\text { Changes in cerebral glucose metabolism after } 3 \text { weeks of } \\
\text { non-invasive electrical stimulation of mild cognitive impairment } \\
\text { patients }\end{array}$ & Yun et al., 2016 & South Korea & included \\
\hline & & 27381076 & $\begin{array}{l}\text { Brain stimulation during an afternoon nap boosts slow oscillatory } \\
\text { activity and memory consolidation in older adults }\end{array}$ & Ladenbauer et al., 2016 & Germany & excluded, (2) \\
\hline & & 27178247 & $\begin{array}{l}\text { Older adults improve on everyday tasks after working memory } \\
\text { training and neurostimulation }\end{array}$ & $\begin{array}{l}\text { Stephens and Berryhill, } \\
2016\end{array}$ & USA & excluded, (2) \\
\hline \multirow[t]{2}{*}{ tDCS, aging } & 24 & 24062685 & $\begin{array}{l}\text { Enhancing verbal episodic memory in older and young subjects } \\
\text { after non-invasive brain stimulation }\end{array}$ & Manenti et al., 2013 & Italy & excluded, (2) \\
\hline & & 26696882 & $\begin{array}{l}\text { No significant effect of prefrontal tDCS on working memory } \\
\text { performance in older adults }\end{array}$ & Nilsson et al., 2015 & Sweden & excluded, (2) \\
\hline $\begin{array}{l}\text { Transcranial direct current stimulation } \\
\text { (or tDCS), older }\end{array}$ & 5 & 27247261 & $\begin{array}{l}\text { Boosting slow oscillatory activity using tDCS during early nocturnal } \\
\text { slow wave sleep does not improve memory consolidation in } \\
\text { healthy older adults }\end{array}$ & Paßmann et al., 2016 & Germany & excluded, (2) \\
\hline $\begin{array}{l}\text { Transcranial direct current stimulation, } \\
\text { cognition, aging }\end{array}$ & 19 & 28062255 & $\begin{array}{l}\text { Differential effects of bihemispheric and unihemispheric } \\
\text { transcranial direct current stimulation in young and elderly adults in } \\
\text { verbal learning }\end{array}$ & Fiori et al., 2017 & Italy & included \\
\hline $\begin{array}{l}\text { Transcranial direct current stimulation } \\
\text { (or tDCS), memory, aging }\end{array}$ & 25 & 26116933 & $\begin{array}{l}\text { Memory improvement via slow-oscillatory stimulation during sleep } \\
\text { in older adults }\end{array}$ & Westerberg et al., 2015 & USA & included \\
\hline
\end{tabular}


TABLE 1 | Continued

\begin{tabular}{|c|c|c|c|c|c|c|}
\hline Keywords (or other search key) & $\begin{array}{c}\# \\
\text { Studies }\end{array}$ & $\begin{array}{l}\text { Selected } \\
\text { studies } \\
\text { (PMID) }\end{array}$ & Title & References & Country & $\begin{array}{l}\text { Consideration } \\
\text { for review* }\end{array}$ \\
\hline \multirow[t]{5}{*}{ tDCS, memory } & 34 & 24678298 & $\begin{array}{l}\text { Anodal tDCS during face-name associations memory training in } \\
\text { Alzheimer's patients }\end{array}$ & Cotelli et al., 2014 & Italy & excluded, (4) \\
\hline & & 22016735 & $\begin{array}{l}\text { Improved proper name recall in aging after electrical stimulation of } \\
\text { the anterior temporal lobes }\end{array}$ & Ross et al., 2011 & USA & excluded, (3) \\
\hline & & 28485663 & $\begin{array}{l}\text { Can } 8 \text { months of daily tDCS application slow the cognitive decline } \\
\text { in Alzheimer's disease? A case study }\end{array}$ & Bystad et al., 2017 & Norway & excluded, (5) \\
\hline & & 28509625 & $\begin{array}{l}\text { Direct-current stimulation does little to improve the outcome of } \\
\text { working memory training in older adults }\end{array}$ & Nilsson et al., 2017 & Sweden & excluded, (3) \\
\hline & & 26250473 & $\begin{array}{l}\text { Effects of transcranial direct current stimulation upon attention and } \\
\text { visuoperceptual function in Lewy body dementia: A preliminary } \\
\text { study }\end{array}$ & Elder et al., 2016 & UK & excluded, (1) \\
\hline \multirow[t]{7}{*}{$\begin{array}{l}\text { Transcranial direct current stimulation } \\
\text { (or tDCS), memory, aged }\end{array}$} & 44 & 28934620 & $\begin{array}{l}\text { Clinical utility and tolerability of transcranial direct current } \\
\text { stimulation in mild cognitive impairment }\end{array}$ & Murugaraja et al., 2017 & India & excluded, (2) \\
\hline & & 28637840 & $\begin{array}{l}\text { Promoting sleep oscillations and their functional coupling by } \\
\text { transcranial stimulation enhances memory consolidation in mild } \\
\text { cognitive impairment }\end{array}$ & Ladenbauer et al., 2017 & Germany & excluded, (2) \\
\hline & & 27653887 & $\begin{array}{l}\text { At-home tDCS of the left dorsolateral prefrontal cortex improves } \\
\text { visual short-term memory in mild vascular dementia }\end{array}$ & André et al., 2016 & Germany & excluded, (1) \\
\hline & & 27005937 & $\begin{array}{l}\text { Transcranial direct current stimulation as a memory enhancer in } \\
\text { patients with Alzheimer's disease: A randomized, } \\
\text { placebo-controlled trial }\end{array}$ & Bystad et al., 2016 & Norway & included \\
\hline & & 31529691 & $\begin{array}{l}\text { Randomized controlled trial of tDCS on cognition in } 201 \text { seniors } \\
\text { with mild neurocognitive disorder }\end{array}$ & Lu et al., 2019 & Hong Kong & included \\
\hline & & 26499250 & $\begin{array}{l}\text { Would transcranial direct current stimulation (tDCS) enhance the } \\
\text { effects of working memory training in older adults with mild } \\
\text { neurocognitive disorder due to Alzheimer's disease: Study } \\
\text { protocol for a randomized controlled trial }\end{array}$ & Cheng et al., 2015 & Hong Kong & $\begin{array}{l}\text { excluded, (4); } \\
\text { actual study: PMID } \\
31529691\end{array}$ \\
\hline & & 28390970 & $\begin{array}{l}\text { Transcranial direct current stimulation can enhance working } \\
\text { memory in Huntington's disease }\end{array}$ & Eddy et al., 2017 & UK & excluded, (7) \\
\hline $\begin{array}{l}\text { Transcranial direct current stimulation, } \\
\text { cognition, aged }\end{array}$ & 48 & 25379604 & $\begin{array}{l}\text { Transcranial direct current stimulation and cognitive training in the } \\
\text { rehabilitation of Alzheimer's disease: A case study }\end{array}$ & Penolazzi et al., 2015 & Italy & excluded, (5) \\
\hline Found in a review & 1 & 23884951 & $\begin{array}{l}\text { Anodal transcranial direct current stimulation temporarily reverses } \\
\text { age-associated cognitive decline and functional brain activity } \\
\text { changes }\end{array}$ & Meinzer et al., 2013 & Germany & included \\
\hline Found in a previously listed paper & 1 & 25346688 & $\begin{array}{l}\text { A double-blind randomized clinical trial on the efficacy of cortical } \\
\text { direct current stimulation for the treatment of Alzheimer's disease }\end{array}$ & Khedr et al., 2014 & Egypt & included \\
\hline $\begin{array}{l}\text { Transcranial direct current stimulation, } \\
\text { memory }\end{array}$ & 194 & 27555381 & $\begin{array}{l}\text { Effects of anodal transcranial direct current stimulation and } \\
\text { serotonergic enhancement on memory performance in young and } \\
\text { older adults }\end{array}$ & Prehn et al., 2017 & Germany & included \\
\hline
\end{tabular}


TABLE 1 | Continued

\begin{tabular}{|c|c|c|c|c|c|c|}
\hline Keywords (or other search key) & $\begin{array}{c}\# \\
\text { Studies }\end{array}$ & $\begin{array}{l}\text { Selected } \\
\text { studies } \\
\text { (PMID) }\end{array}$ & Title & References & Country & $\begin{array}{l}\text { Consideration } \\
\text { for review* }\end{array}$ \\
\hline Manenti, Sandrini & 4 & 29259554 & $\begin{array}{l}\text { Strengthening of existing episodic memories through non-invasive } \\
\text { stimulation of prefrontal cortex in older adults with subjective } \\
\text { memory complaints }\end{array}$ & Manenti et al., 2017 & Italy & included \\
\hline \multirow[t]{3}{*}{ Ferrucci } & 41 & 18525028 & $\begin{array}{l}\text { Transcranial direct current stimulation improves recognition } \\
\text { memory in Alzheimer's disease }\end{array}$ & Ferrucci et al., 2008 & Italy & included \\
\hline & & 16843494 & $\begin{array}{l}\text { Effects of transcranial direct current stimulation on working } \\
\text { memory in patients with Parkinson's disease }\end{array}$ & Boggio et al., 2006 & Brazil & excluded, (2) \\
\hline & & 21840288 & $\begin{array}{l}\text { Prolonged visual memory enhancement after direct current } \\
\text { stimulation in Alzheimer's disease }\end{array}$ & Boggio et al., 2012 & Italy, Brazil & included \\
\hline Berryhill, Jones & 9 & 22684095 & $\begin{array}{l}\text { tDCS selectively improves working memory in older adults with } \\
\text { more education }\end{array}$ & Berryhill and Jones, 2012 & USA & excluded, (2) \\
\hline \multirow[t]{4}{*}{$\begin{array}{l}\text { PubMed studies (that will be added to } \\
\text { tDCS database) }\end{array}$} & 4 & 29736192 & $\begin{array}{l}\text { The effects of transcranial direct current stimulation on the } \\
\text { cognitive functions in older adults with mild cognitive impairment: } \\
\text { A pilot study }\end{array}$ & Cruz Gonzalez et al., 2018 & Hong Kong & included \\
\hline & & 30395314 & $\begin{array}{l}\text { Effects of transcranial direct current stimulation on episodic } \\
\text { memory in amnestic mild cognitive impairment: A pilot study }\end{array}$ & Manenti et al., 2020 & Italy or UK & excluded, (6) \\
\hline & & 29313802 & $\begin{array}{l}\text { Augmenting cognitive training in older adults (The ACT Study): } \\
\text { Design and Methods of a Phase III tDCS and cognitive training trial }\end{array}$ & Woods et al., 2018 & USA & excluded, (4) \\
\hline & & 30783198 & $\begin{array}{l}\text { tDCS-induced episodic memory enhancement and its association } \\
\text { with functional network coupling in older adults }\end{array}$ & Antonenko et al., 2019 & Germany & excluded, (2) \\
\hline
\end{tabular}

${ }^{*}$ Results tabulated include studies prior to application of inclusion/exclusion criteria with indication whether the study was included or excluded as well as reasons for exclusion. *Reasons for exclusion: (1) cognitive (declarative or working memory) outcome measures of tDCS effects are not a focus of the study, (2) study design insufficient (single-blinded, not sham/placebo controlled), (3) blinding procedure not recorded, (4) publication only contains study protocol, (5) case study, (6) restricted access to the paper until submission of this review, (7) age criterion not fulfilled. 
search for "transcranial direct current stimulation" or "tDCS," "memory" and "aged" resulted in 44 and for "transcranial direct current stimulation," "cognition" and "aged" in 48 studies of which a total number of eight studies remained after abstract selection. Two more studies were found and included as they were cited in a review or one of the previously included papers. Finally, the keywords "transcranial direct current stimulation" and "memory" only returned 1 more relevant study out of 194 results as other appropriate papers were already included. Based on further evidence for relevant studies extracted from previous inclusions an author search for "Manenti" and "Sandrini" (four results), "Ferrucci" (41 results) and "Berryhill" and "Jones" (nine results) returned five other relevant studies. These were not found previously as they did not contain the keywords "transcranial direct current stimulation." Four more recently published studies that seemed relevant were only available on PubMed but will subsequently be added to the tDCS database upon approval. The abstract screening eventually resulted in a list of 42 publications (Table 1) that were precisely filtered according to exclusion and inclusion criteria so that 16 studies remained to be reviewed (Table 2).

\section{RESULTS \\ Overview}

The 16 studies that met all inclusion criteria were performed between 2008 and 2019 (more recent publications had to be excluded, see Table 1) and included 543 subjects comprising $60.8 \%$ females and $39.2 \%$ males. Thirty-eight subjects dropped out during the course of the respective study making a total dropout rate of $7.1 \%$. All older participants were aged between 50 and 90 years (only 2 studies included younger control groups). Five out of 16 studies included only healthy elderlies (Meinzer et al., 2013; Westerberg et al., 2015; Sandrini et al., 2016; Fiori et al., 2017; Prehn et al., 2017), while the remaining studies applied tDCS to patients suffering from MCI, subjective memory decline (SMC), neurocognitive disorder due to AD (NCD-AD) or probable as well as mild to moderate $\mathrm{AD}$ (Ferrucci et al., 2008; Boggio et al., 2012; Cotelli et al., 2014; Khedr et al., 2014; Meinzer et al., 2015; Bystad et al., 2016; Yun et al., 2016; Manenti et al., 2017; Cruz Gonzalez et al., 2018; Im et al., 2019; Lu et al., 2019). In order to evaluate the effectiveness of tDCS protocols applied to patients suffering from different age-associated diseases, the results section considers outcomes in healthy subjects and patients with the above listed cognitive diseases separately. Thereby, we aim to provide an overview of limitations and successes of tDCS in patients in comparison to healthy individuals. We think that efficient stimulation methodologies to treat age-related cognitive decline can only be proposed when considering disease-related variability in tDCS efficiency. Variability may exist when comparing applications in healthy vs. diseased brains but also in the different ageassociated diseases as well as different disease states due to varying degrees of progression of neurodegeneration or different brain areas affected.

\section{TDCS in Healthy Elderly People}

To begin with, assuming that $\mathrm{tDCS}$ has the potential to modulate cognitive functions in healthy aging, Meinzer et al. combined anodal tDCS during an overt semantic learning task with functional magnetic resonance imaging (fMRI) to investigate effects on task performance as well as local brain activity. The main outcome of this study was enhanced word retrieval and restoring of "youth-like" network connectivity in old subjects after receiving unihemispheric anodal tDCS to the left ventral inferior frontal gyrus in comparison to the old and young sham groups (Meinzer et al., 2013). Based on this, Fiori et al. tried to assess whether bihemispheric tDCS over temporo-parietal areas (with the anode on the left and the cathode on the right contralateral hemisphere) differently impacts the performance in a verbal learning task in old vs. young subjects in comparison to unihemispheric tDCS. Here, stimulation did not affect the performance in young participants while older subjects seemed to profit from bihemispheric tDCS manifested in significantly higher numbers of correctly retrieved words (Fiori et al., 2017). Both studies referred to evidence on age-related altered network connectivity and aimed to compensate for "bihemispehric hyperactivities." Another study investigated combined effects of tDCS and selective serotonin reuptake inhibitors (SSRIs) on healthy cognition in elderly people (Prehn et al., 2017). Prehn et al. assumed that this combination of two potential cognitionenhancing methodologies might lead to synergistic effects and thus ameliorate memory performance. The assessment of objectlocation learning indicated that a combination of SSRIs and tDCS but not single-modality treatment improved immediate memory but surprisingly worsened learning performance in comparison to other conditions. However, this was one of the only studies placing the anode on the right (temporal) cortex (Prehn et al., 2017). Sandrini et al. showed that anodal tDCS over the left dorso-lateral prefrontal cortex (LDLPFC) improved delayed recall in comparison to sham tDCS in old subjects after a verbal episodic memory task when applied during the learning phase (Sandrini et al., 2016). Finally, Westerberg et al. applied bilateral anodal sinusoidal slow-oscillatory tDCS (sotDCS) with a frequency of $0.75 \mathrm{~Hz}$ to the mid-lateral frontal cortex of healthy elderlies during sleep, hypothesizing that agerelated memory decline could be a consequence of decreased memory consolidation during altered sleep upon aging. So-tDCS enhanced verbal recall in old participants in comparison to sham so-tDCS and slow-oscillatory activity in the frontal lobe (Westerberg et al., 2015).

\section{TDCS in Age-Associated Diseases Mild Cognitive Impairment and Subjective Memory Complaints}

Expanding their examinations on the potential of tDCS to counteract cognitive decline, Meinzer et al. performed another study applying a similar tDCS and fMRI methodologies as in Meinzer et al. (2013) to patients with MCI (Meinzer et al., 2015). In baseline conditions patients performed significantly worse in a word retrieval task compared to elderly healthy controls. However, word-retrieval performance was significantly ameliorated up to the level of controls after anodal tDCS over 
TABLE 2 | Summary of all studies reviewed including most important features and tDCS parameters.

\begin{tabular}{|c|c|c|c|c|c|c|c|c|c|}
\hline \multirow{2}{*}{$\begin{array}{l}\text { References } \\
\text { (PMID) }\end{array}$} & \multirow[t]{2}{*}{ Study design } & \multirow{2}{*}{$\begin{array}{l}\text { Participants } \\
\text { (N, female/male, age } \\
{[\text { mean } \pm \mathrm{SD} \text { and/or }} \\
\text { range], condition*) }\end{array}$} & \multirow[t]{2}{*}{ Drop-outs } & \multicolumn{5}{|c|}{ Stimulation parameters } & \multirow{2}{*}{$\begin{array}{l}\text { Behavioral } \\
\text { (cognitive) } \\
\text { effects }\end{array}$} \\
\hline & & & & Montage & Intensity & Duration & $\begin{array}{l}\text { \# Active } \\
\text { tDCS } \\
\text { sessions }\end{array}$ & $\begin{array}{l}\text { Timepoint of } \\
\text { tDCS }\end{array}$ & \\
\hline Im et al. (2019) (31196835) & $\begin{array}{l}\text { Sham-controlled, } \\
\text { double-blinded, } \\
\text { randomized }\end{array}$ & $\begin{array}{l}N=18,15 / 3,73.4,60-85 \\
\text { early } A D\end{array}$ & 2 & Anode F3, cathode F4 & $2 \mathrm{~mA}$ & $30 \mathrm{~min}$ & $\begin{array}{l}\text { Every day for } 6 \\
\text { months }\end{array}$ & Baseline & + \\
\hline $\begin{array}{l}\text { Sandrini et al. (2016) } \\
\text { (26923418) }\end{array}$ & $\begin{array}{l}\text { Sham-controlled, } \\
\text { double-blinded, } \\
\text { randomized }\end{array}$ & $\begin{array}{l}N=28,17 / 11,68.9 \\
\text { healthy }\end{array}$ & None & $\begin{array}{l}\text { Anode F3, cathode right } \\
\text { supraorbital region }\end{array}$ & $1.5 \mathrm{~mA}$ & $15 \min$ & Up to 5 & $\begin{array}{l}\text { During learning } \\
\text { phase }\end{array}$ & + \\
\hline $\begin{array}{l}\text { Meinzer et al. (2015) } \\
\text { (25449530) }\end{array}$ & $\begin{array}{l}\text { Sham-controlled, } \\
\text { double-blinded, } \\
\text { randomized, } \\
\text { counterbalanced }\end{array}$ & $\begin{array}{l}N=36,14 / 22,69.56 \pm \\
5.56 \text { (healthy group), } 67.44 \\
\pm 7.27 \text { (MCl group), healthy } \\
\text { and } \mathrm{MCl}\end{array}$ & None & $\begin{array}{l}\text { Anode left ventral IFG, } \\
\text { cathode right supraorbital } \\
\text { area }\end{array}$ & $1 \mathrm{~mA}$ & $20 \min$ & 1 & $\begin{array}{l}\text { During rs- and } \\
\text { task-related fMRI } \\
\text { (semantic word } \\
\text { retrieval) }\end{array}$ & + \\
\hline Yun et al. (2016) (27903289) & $\begin{array}{l}\text { Sham-controlled, } \\
\text { double-blinded, } \\
\text { randomized }\end{array}$ & $\begin{array}{l}N=16,11 / 5,73.9,65-86 \\
\mathrm{MCl}\end{array}$ & None & Anode F3, cathode F4 & $2 \mathrm{~mA}$ & $30 \mathrm{~min}$ & 9 (in 3 weeks) & Baseline & + \\
\hline Fiori et al. (2017) (28062255) & $\begin{array}{l}\text { Sham-controlled, } \\
\text { double-blinded, } \\
\text { randomized, } \\
\text { counterbalanced }\end{array}$ & $\begin{array}{l}N=30,29 \pm 620-40 \\
\text { (young group), } 72 \pm 6 \\
60-80 \text { (old group), healthy }\end{array}$ & None & $\begin{array}{l}\text { Unihemispheric: anode } \\
\text { CP5, cathode right } \\
\text { orbito-frontal cortex; } \\
\text { bihemispheric: anode CP5 } \\
\text { cathode CP4 }\end{array}$ & $2 \mathrm{~mA}$ & $20 \mathrm{~min}$ & $\begin{array}{l}2 \text { (uni- and } \\
\text { bi-hemispheric) }\end{array}$ & $\begin{array}{l}\text { During retrieval } \\
\text { phase }\end{array}$ & + \\
\hline $\begin{array}{l}\text { Westerberg et al. (2015) } \\
\text { (26116933) }\end{array}$ & $\begin{array}{l}\text { Sham-controlled, } \\
\text { double-blinded, } \\
\text { randomized }\end{array}$ & $\begin{array}{l}N=18,16 / 3,73.465-85 \\
\text { healthy }\end{array}$ & None & $\begin{array}{l}\text { Anodes F7 and F8, } \\
\text { references to ipsilateral } \\
\text { mastoids }\end{array}$ & $\begin{array}{l}\text { so-tDCS: } \\
0.75 \mathrm{~Hz} \\
0-260 \mu \mathrm{A}\end{array}$ & $\begin{array}{l}5 \text { times } \\
5 \mathrm{~min}\end{array}$ & 1 & During sleep & + \\
\hline $\begin{array}{l}\text { Cotelli et al. (2014) } \\
\text { (24678298) }\end{array}$ & $\begin{array}{l}\text { Sham-controlled, } \\
\text { double-blinded, } \\
\text { randomized }\end{array}$ & $\begin{array}{l}N=36,29 / 7,76.5 \\
\text { probable mild to moderate } \\
A D\end{array}$ & $\begin{array}{l}2 \text { before } \\
\text { 3-months, } 4 \\
\text { before } \\
6 \text {-months } \\
\text { follow-up }\end{array}$ & $\begin{array}{l}\text { Anode left DLPFC ( } 8 \mathrm{~cm} \\
\text { frontally, } 6 \mathrm{~cm} \text { laterally), } \\
\text { cathode right deltoid muscle }\end{array}$ & $2 \mathrm{~mA}$ & $25 \min$ & 10 (in 2 weeks) & $\begin{array}{l}\text { During memory or } \\
\text { motor training }\end{array}$ & - \\
\hline $\begin{array}{l}\text { Bystad et al. (2016) } \\
\text { (27005937) }\end{array}$ & $\begin{array}{l}\text { Sham-controlled, } \\
\text { double-blinded, } \\
\text { randomized }\end{array}$ & $\begin{array}{l}N=25,14 / 11,72.5(\mathrm{AD} \\
\text { group); } N=22,18 / 4,68.8 \\
\pm 6.8,59-83 \text { (healthy } \\
\text { group), AD and healthy }\end{array}$ & None & Anode T3, cathode FP2 & $2 \mathrm{~mA}$ & $30 \mathrm{~min}$ & 6 (in 10 days) & Baseline & - \\
\hline Lu et al. (2019) (31529691) & $\begin{array}{l}\text { Sham-controlled, } \\
\text { double-blinded, } \\
\text { randomized }\end{array}$ & $\begin{array}{l}N=173,108 / 65,74 \\
60-90, N C D-A D\end{array}$ & 28 & $\begin{array}{l}\text { Anode T3, cathode } \\
\text { contralateral upper limb }\end{array}$ & $2 \mathrm{~mA}$ & $20 \mathrm{~min}$ & 12 (in 3 weeks) & $\begin{array}{l}\text { During WM } \\
\text { training }\end{array}$ & + \\
\hline $\begin{array}{l}\text { Meinzer et al. (2013) } \\
\text { (23884951) }\end{array}$ & $\begin{array}{l}\text { Sham-controlled, } \\
\text { double-blinded, } \\
\text { within-subject }\end{array}$ & $\begin{array}{l}N=20,10 / 10,26.4 \pm 3.4 \\
19-31 \text { (young group), } 68 \pm \\
5.760-76 \text { (old group), } \\
\text { healthy }\end{array}$ & None & $\begin{array}{l}\text { Anode left ventral IFG, } \\
\text { cathode right supraorbital } \\
\text { area }\end{array}$ & $1 \mathrm{~mA}$ & $20 \min$ & 1 & $\begin{array}{l}\text { During rs- and } \\
\text { task-related fMRI } \\
\text { (semantic word } \\
\text { retrieval) }\end{array}$ & + \\
\hline
\end{tabular}


TABLE 2 | Continued

\begin{tabular}{|c|c|c|c|c|c|c|c|c|c|}
\hline \multirow{2}{*}{$\begin{array}{l}\text { References } \\
\text { (PMID) }\end{array}$} & \multirow[t]{2}{*}{ Study design } & \multirow{2}{*}{$\begin{array}{l}\text { Participants } \\
\text { (N, female/male, age } \\
{[\text { [mean } \pm \mathrm{SD} \text { and/or }} \\
\text { range], condition*) }\end{array}$} & \multirow[t]{2}{*}{ Drop-outs } & \multicolumn{5}{|c|}{ Stimulation parameters } & \multirow{2}{*}{$\begin{array}{l}\text { Behavioral } \\
\text { (cognitive) } \\
\text { effects }\end{array}$} \\
\hline & & & & Montage & Intensity & Duration & $\begin{array}{l}\text { \# Active } \\
\text { tDCS } \\
\text { sessions }\end{array}$ & $\begin{array}{l}\text { Timepoint of } \\
\text { tDCS }\end{array}$ & \\
\hline $\begin{array}{l}\text { Khedr et al. (2014) } \\
\text { (25346688) }\end{array}$ & $\begin{array}{l}\text { Sham-controlled, } \\
\text { double-blinded, } \\
\text { randomized }\end{array}$ & $\begin{array}{l}N=34,15 / 19,69.7 \pm 4.8 \\
62-79, \text { mild to moderate } A D\end{array}$ & None & $\begin{array}{l}\text { atDCS: anode LDLPFC, } \\
\text { cathode contralateral } \\
\text { supraorbital region; ctDCS: } \\
\text { vice versa }\end{array}$ & $2 \mathrm{~mA}$ & $25 \min$ & $\begin{array}{l}10 \text { consecutive } \\
\text { days }\end{array}$ & Baseline & + \\
\hline $\begin{array}{l}\text { Prehn et al. (2017) } \\
\text { (27555381) }\end{array}$ & $\begin{array}{l}\text { Sham-controlled, } \\
\text { double-blinded, } \\
\text { randomized }\end{array}$ & $\begin{array}{l}N=39,23 / 17,24 \pm 4 \\
18-35 \text { (young group), } 66 \pm \\
750-80 \text { (old group), healthy }\end{array}$ & 1 & $\begin{array}{l}\text { Anode T6, cathode } \\
\text { contralateral frontopolar } \\
\text { cortex }\end{array}$ & $1 \mathrm{~mA}$ & $20 \mathrm{~min}$ & 2 & $\begin{array}{l}\text { During learning } \\
\text { phase }\end{array}$ & + \\
\hline $\begin{array}{l}\text { Manenti et al. (2017) } \\
\text { (2925955) }\end{array}$ & $\begin{array}{l}\text { Sham-controlled, } \\
\text { double-blinded, } \\
\text { randomized }\end{array}$ & $\begin{array}{l}N=22,14 / 8,74.5 \pm 5.9 \\
S M C\end{array}$ & None & $\begin{array}{l}\text { Anode F3, cathode right } \\
\text { supraorbital area }\end{array}$ & $1.5 \mathrm{~mA}$ & $15 \mathrm{~min}$ & 1 & $\begin{array}{l}\text { After learning } \\
\text { phase but before } \\
\text { recall }\end{array}$ & + \\
\hline $\begin{array}{l}\text { Ferrucci et al. (2008) } \\
\text { (18525028) }\end{array}$ & $\begin{array}{l}\text { Sham-controlled, } \\
\text { double-blinded, } \\
\text { randomized, } \\
\text { cross-balanced }\end{array}$ & $\begin{array}{l}N=10,7 / 3,75.2 \pm 7.3 \\
64-84, \text { probable } A D\end{array}$ & None & $\begin{array}{l}\text { Anode P3-T5 left and P6-T4 } \\
\text { right, cathode contralateral } \\
\text { deltoid muscle }\end{array}$ & $1.5 \mathrm{~mA}$ & $15 \min$ & $\begin{array}{l}2 \text { (anodal and } \\
\text { cathodal) }\end{array}$ & Between tasks & + \\
\hline $\begin{array}{l}\text { Boggio et al. (2012) } \\
\text { (21840288) }\end{array}$ & $\begin{array}{l}\text { Sham-controlled, } \\
\text { double-blinded, } \\
\text { randomized, } \\
\text { counterbalanced }\end{array}$ & $\begin{array}{l}N=15,7 / 8,77.5 \pm 6.9 \\
\text { (Italian group), } 80.6 \pm 9.5 \\
\text { (Brazilian group), AD }\end{array}$ & None & $\begin{array}{l}\text { Anodes bilaterally } \mathrm{T} 3 \text { and } \\
\mathrm{T} 4 \text {, cathode right deltoid } \\
\text { muscle }\end{array}$ & $2 \mathrm{~mA}$ & $30 \mathrm{~min}$ & $\begin{array}{l}5 \text { consecutive } \\
\text { days }\end{array}$ & Baseline & + \\
\hline $\begin{array}{l}\text { Cruz Gonzalez et al. (2018) } \\
\text { (29736192) }\end{array}$ & $\begin{array}{l}\text { Sham-controlled, } \\
\text { single-subject study } \\
\text { A-B-C-A design }\end{array}$ & $\begin{array}{l}N=5,2 / 3,72.8 \pm 6.6 \\
67-81, \mathrm{MCl}\end{array}$ & $\begin{array}{l}1 \text { before last } \\
\text { baseline } \\
\text { session }\end{array}$ & $\begin{array}{l}\text { Anode F3, cathode } \\
\text { contralateral deltoid muscle }\end{array}$ & $2 \mathrm{~mA}$ & $30 \mathrm{~min}$ & $1-5$ (in 1 week) & $\begin{array}{l}\text { During cognitive } \\
\text { training }\end{array}$ & + \\
\hline
\end{tabular}

Disease conditions: *AD, Alzheimer's Disease; SCD, subjective cognitive decline; MCl, mild cognitive impairment; NCD-AD, neurocognitive disorder due to Alzheimer's Disease; SMC, subjective memory complaints. 
the left ventral IFG (Meinzer et al., 2015). Yun et al. found that repeated application of anodal tDCS over the DLPFC (nine times $30 \mathrm{~min}$ in 3 weeks) significantly increased brain metabolism in MCI patients (measured by FDG-PET) and enhanced memory performance compared to sham tDCS (Yun et al., 2016). Anodal tDCS applied over the left lateral PFC after learning and before recall of an episodic memory task in patients with subjective memory complaints (SMC) significantly increased word recognition performance up 30 days after learning in comparison to the sham group (Manenti et al., 2017). Moreover, in a pilot study of Cruz Gonzalez et al. anodal or cathodal tDCS over the DLPFC was combined with cognitive training during stimulation to synergistically enhance declined cognition in MCI. Tendencies of increased processing speed, selective attention, working memory activities, and the completion time in planning ability and divided attention tasks were observed for both anodal and cathodal stimulation in comparison to sham tDCS. However, due to the small sample size and the lack of randomization, results were highly variable and need further investigation and confirmation (Cruz Gonzalez et al., 2018). The biggest study (including 201 participants) has been performed by $\mathrm{Lu}$ et al. who also combined tDCS over left temporal areas and (working) memory training in patients with neurocognitive disorder due to AD (NCD-AD). Participants underwent 12 sessions of anodal tDCS in 3 weeks and performed working memory tasks during stimulation. Performance significantly increased up to 8 or even 12 weeks post-intervention in secondary outcome measures (delayed recall, working memory tests, logical memory) for subjects receiving tDCS and working memory training compared to control groups. However, primary outcomes (global cognition measured by ADAS-Cog and the working memory training performance) improved throughout all groups without stimulation-dependent differences (Lu et al., 2019).

\section{Alzheimer's Disease}

Two of the first small studies to investigate tDCS in patients with $\mathrm{AD}$ were performed by Ferrucci et al. in 2008 and Boggio et al. in 2012. Ferrucci et al. applied anodal and cathodal tDCS to the temporo-parietal cortex and were able to show that a single session of anodal tDCS significantly increased accuracy in a word recognition task while cathodal tDCS had contrary effects. However, no stimulation-type-dependent changes in reaction times were found based on the assessment of a visual attention task (Ferrucci et al., 2008). Subsequently, Boggio et al. used bilateral anodal tDCS applied for five consecutive days over the temporal cortex, which significantly ameliorated performance of $\mathrm{AD}$ patients in a visual recognition task but not in a visual attention task compared to sham tDCS (Boggio et al., 2012). Examining longer-term effects of 10 sessions of anodal tDCS over the LDLPFC on cognitive abilities in AD, Khedr et al. found that MMSE scores significantly improved for both anodal and cathodal stimulation compared to sham tDCS even 2 months post-intervention (Khedr et al., 2014). Cotelli et al. also applied 10 sessions of tDCS over the LDLPFC in AD patients but combined with individualized memory training during stimulation. This study failed to show a significant effect of anodal tDCS on memory performance in AD (Cotelli et al., 2014). Similarly, Bystad et al. could not reveal significant effects of anodal tDCS applied over the left temporal cortex in subjects suffering from AD. Verbal memory test scores did not differ significantly after active stimulation in comparison to sham. However, a tendency of increased delayed recall was observed for the group receiving active tDCS (Bystad et al., 2016). Finally, the findings of Im et al., who studied the effects of 6-months daily at home tDCS in $\mathrm{AD}$ patients, were in line with Khedr et al. (2014). The main outcomes were significant benefits of anodal tDCS on global cognition assessed via MMSE and improved language function based on ameliorated performance in the Boston Naming Test (BNT), stabilization of some executive functions in $\mathrm{AD}$ patients compared to patients receiving sham stimulation as well as increased cerebral glucose metabolism (Im et al., 2019).

\section{DISCUSSION}

\section{Methodological Considerations}

In the 16 reviewed studies tDCS intensity varied between 1 and $2 \mathrm{~mA}$ [except for the study of Westerberg et al. (2015) who applied so-tDCS with a frequency of $0.75 \mathrm{~Hz}$ and $0-260 \mu \mathrm{A}$ intensity], one session lasted between 15 and $30 \mathrm{~min}$ and for most studies the number of sessions varied between 1 and 10 (Figure 2). Exceptions in session number were the study of Lu et al. (2019) who applied 12 sessions of tDCS and Im et al. (2019) who chose to use daily at home tDCS over 6 months to treat patients with AD (Figure 2).

In the majority of applications stimulation intensity was rather high $(2 \mathrm{~mA})$ and most of the sessions lasted 25-30 min. Importantly, none of the studies reported severe adverse effects resulting from tDCS or so-tDCS. In 3 studies (Khedr et al., 2014; Sandrini et al., 2016; Lu et al., 2019) rarely occurring mild side effects were skin irritation, itching, and redness under the area of the electrodes. In only 2 studies (Prehn et al., 2017; Cruz Gonzalez et al., 2018) a few subjects reported a mild headache and dizziness after the stimulation, which only lasted for several hours. However, the occurrence of mild adverse effects did not seem to correlate with the magnitude of stimulation intensity, session duration or session number.

A more precise investigation of electrode montage revealed that 12 out of 16 studies stimulated the left cortical hemisphere, mostly targeting the (pre-)frontal cortex (Figure 3). However, several studies also stimulated temporal or temporo-parietal areas (Figure 3). The difference in stimulation location may be traced back to deviating hypotheses and different aims in modulating cognitive functions. All but 1 study, that targeted the temporal or temporo-parietal cortex, aimed to ameliorate or slow $\mathrm{AD}$ progression, as the medial temporal lobe (MTL), including the hippocampus, is one of the major and earliest affected brain regions in disease (Smith, 2002; Dickerson et al., 2004). The reason for targeting the temporal cortices might be to reach areas that are mainly affected by decline of neuroplasticity due to neurodegeneration and thereby potentially counteract the loss of neuronal connections. Although episodic memory is thought to mainly depend on intact functioning of MTL and hippocampus 


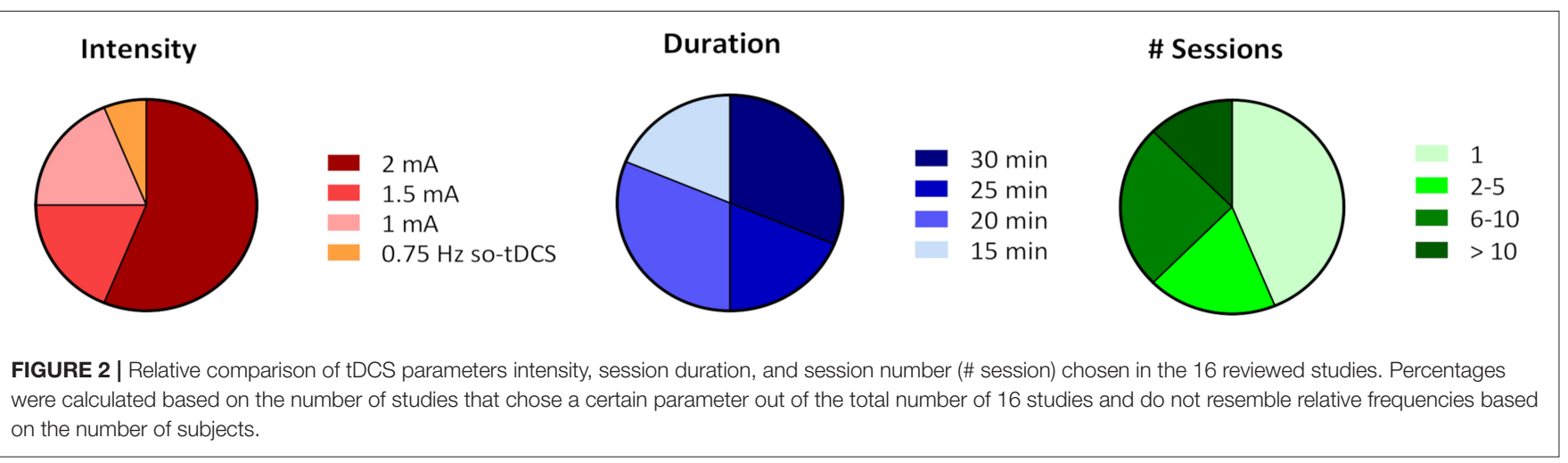

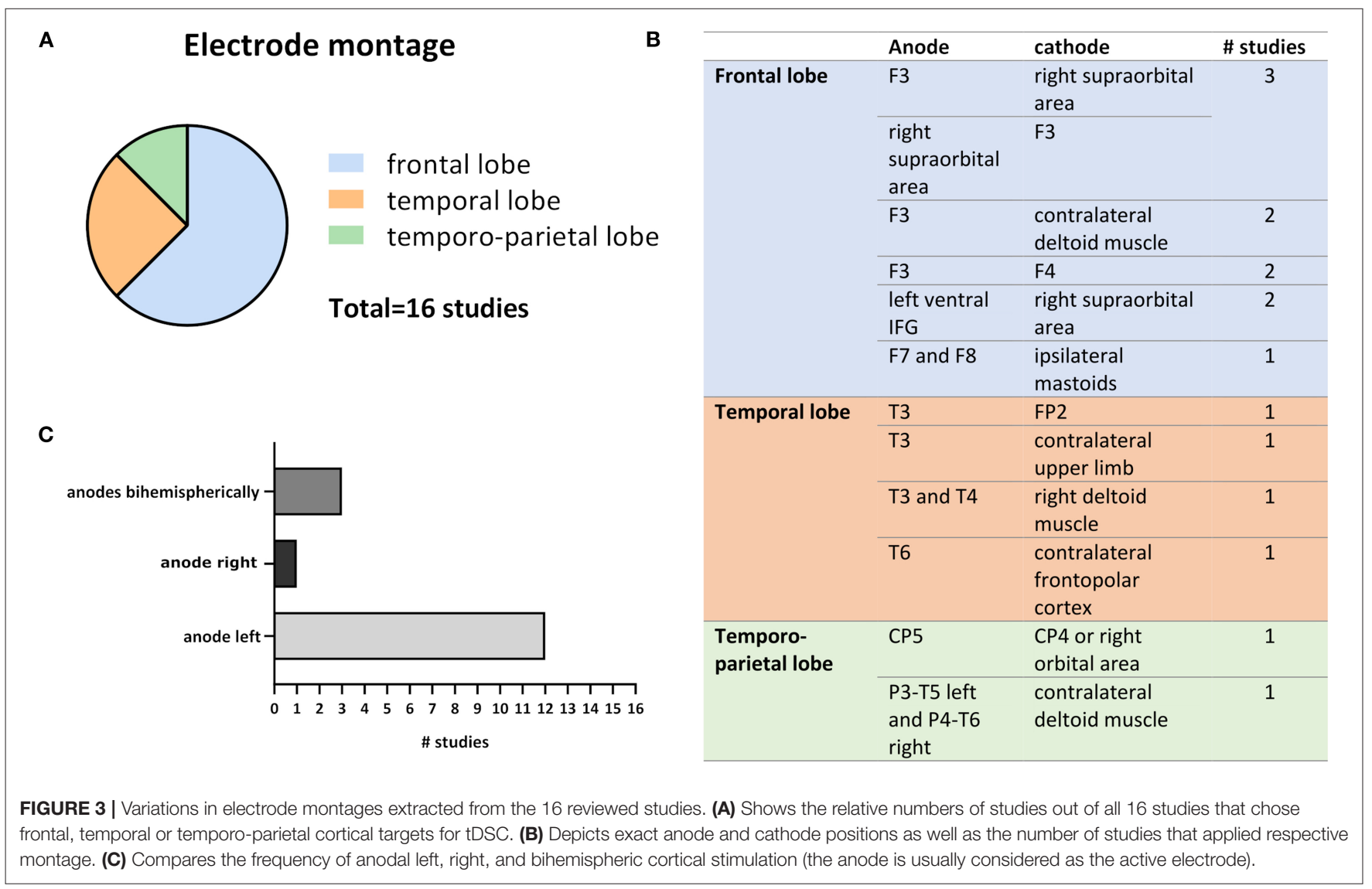

(Dickerson and Eichenbaum, 2010), the PFC and non-disturbed communication between all these areas seem crucial in cognitive processes relying on episodic memory (Fletcher and Henson, 2001; Brem et al., 2013).

Scientists targeting the frontal lobe (mainly the DLPFC) mostly aimed to modify cognitive processes by directly impacting underlying neuronal networks and indirectly subcortical areas (Frith and Dolan, 1996). Of the two studies that failed to show significant effects of tDCS on cognitive functions Cotelli et al. (2014) targeted the LDLPFC, while Bystad et al. (2016) stimulated the left temporal cortex. In both studies the subjects were suffering from $\mathrm{AD}$. Because neuronal network connectivity and synchrony seem to change upon aging (Goh, 2011; Meinzer et al., 2013), further or increased alterations might occur in disease, which should be considered when developing new tDCS protocols to treat patients with cognitive impairment or advanced dementia. It might be beneficial to include individual computational modeling of current distribution to account for structural brain alterations happening upon aging such as atrophy along with raising volumes of the ventricular system (Fjell and Walhovd, 2010). Indeed, increased cerebrospinal fluid (CSF) volume and reduced tissue density significantly impact current distribution throughout the brain (Opitz et al., 2015) as conductivity is higher in more aqueous media and tissues. This 
was further confirmed in a recent study by Antonenko et al. who used computational modeling to show that the cerebral electric field induced by transcranial electrical stimulation is higher for young compared to older people (Antonenko et al., 2021). In the studies reviewed here, mean age of participants differs up to 13 years (Prehn et al., 2017: 66 years; Boggio et al., 2012: 79.1 years) (Table 2) which exemplifies that age differences also occur in studies of the elderly. Age-related electrical field variations may cause controversial results, even when comparing studies performed within similar age groups but with significant mean age deviations. In addition to age-related increase of brain atrophy, individual head anatomy seems to impact the induced electric field strengths (Antonenko et al., 2021). Computational models have shown that large electrodes which are most frequently used in tDCS studies produce large diffuse electric fields in the brain. Not only strengths but also the distributions of these fields are highly dependent on individual head and brain anatomy. Lately, smaller electrodes as well as novel montages, including high-definition tDCS (HD-tDCS) arrangements have been introduced to improve the focality of the stimulation. However, a recent study just reported that better electric field focality was achieved only at the cost of increased interindividual variability (Mikkonen et al., 2020). Nevertheless, another recent study using HD-tDCS and current modeling demonstrated that focal current delivery to the DLPFC with sufficient magnitude of the induced current, modulated the neural activity in older adults (Gbadeyan et al., 2019). However, it remains to be elucidated whether more precise stimulation localization is beneficial in patients suffering from cognitive decline that is mostly caused by neurodegeneration in multiple brain areas affecting widespread cortical networks rather than precisely localized brain regions. Altogether, this highlights the importance of individually predicting the electric field distribution by means of structural brain imaging combined with computational modeling as this may be a crucial factor when applying tDCS to aging brains and lead to decreased effect variability as well as ameliorated spatial accuracy.

The outcomes of the reviewed studies show a high degree of variability-in the results themselves but also in their respective measures (Table 3). Consequently, to reduce variability, the application of multiple and precise cognitive outcome measures that assess a representative range of cognitive functions, is essential when performing tDCS experiments that aim to modulate cognition in the elderly. It seems like the effect of tDCS can sometimes be rather specific for single aspects of human cognition. This might correlate with the part of the cortex that has been stimulated, however, it needs to be pointed out that the spatial resolution of tDCS is rather low. The use of screening tools such as widely applied MMSE or MoCA to evaluate effects on global cognition may be insufficient as these tests resemble a very limited spectrum of cognitive functions and have been developed for quick clinical diagnoses and screenings. Moreover, only few of the reviewed studies included both physiological and cognitive measures. The combination of extensive standardized cognitive assessments with physiological methods such as EEG or fMRI may reveal origins of variability and facilitate the evaluation of tDCS effects.
Out of all studies only three combined tDCS with cognitive training (Cotelli et al., 2014; Cruz Gonzalez et al., 2018; Lu et al., 2019). Even though results depicted here are not very consistent, the idea of synergistic amelioration and intervention of cognitive decline, by combining methods that positively impact cognitive functions in the elderly, seems promising. However, when assessing the effects as well as comparing active to sham stimulation conditions it needs to be considered that cognitive training itself might already improve cognition in both groups. Consequently, effects of tDCS may result in only slight differences that might be hard to detect using semi-sensitive cognitive outcome measures. Further some participants might not respond to the stimulation. A relatively high number of participants is important to properly assess the effects of tDCS on cognition of elderly people. Therefore, future studies may be designed in a multicentric fashion to increase participant numbers and thus reliability of experimental outcomes.

When treating diseases such as MCI or AD, it is crucial to consider long-term (LT) effects of tDCS. We define LT effects as those measured at least 1 week after the end of the intervention. Among the studies reviewed here, only seven examined LT effects (Boggio et al., 2012; Cotelli et al., 2014; Khedr et al., 2014; Sandrini et al., 2016; Manenti et al., 2017; Prehn et al., 2017; Lu et al., 2019) (Table 3), of which only 5 revealed significant results (Boggio et al., 2012; Cotelli et al., 2014; Khedr et al., 2014; Manenti et al., 2017; Lu et al., 2019) meaning that at least one cognitive test score was significantly better at LT timepoints (after stimulation) compared to either baseline (before stimulation) or to the respective control condition (e.g., sham stimulation). When comparing active vs. sham stimulation, only three out of these five studies revealed significant improvement of the active group over the sham group at LT timepoints (Boggio et al., 2012; Khedr et al., 2014; Manenti et al., 2017). Interestingly, the two studies that did not find significant LT effects when comparing active to sham stimulation used a combination therapy of tDCS and cognitive training (Cotelli et al., 2014; Lu et al., 2019). In both studies the tDCS sham group received cognitive training. Taken together, this indicates that, as suggested above, both methods-tDCS and cognitive training-can positively impact cognition in the elderly and both potentially result in LT effects. Whether a combination of both methods enhances LT effects remains to be elucidated. A possible explanation for the absence of LT effects in the remaining two studies (Sandrini et al., 2016; Prehn et al., 2017 ) is that the total time of stimulation (duration of one session multiplied by the number of sessions) applied by Sandrini et al. (15-75 min; stimulation time varied between subjects as stimulation was repeated until a certain test score was achieved) and Prehn et al. (40 min) deviates strongly from the mean time of stimulation $(181 \mathrm{~min})$ of all studies that showed significant LT effects.

\section{Future Perspectives}

In conclusion, based on recently available data (http:// tdcsdatabase.com) to counteract age-associated cognitive decline, anodal tDCS should be applied repeatedly to the left cortical hemisphere. In adulthood, several cognitive processes 
TABLE 3 | Summary of all studies reviewed, listing respective cognitive assessments including the timepoints of the assessment, exact measures, and main outcomes.

\begin{tabular}{|c|c|c|c|}
\hline \multirow[t]{2}{*}{ References } & \multicolumn{3}{|c|}{ Cognitive assessment (to evaluate tDCS effects on cognition) } \\
\hline & Timepoints & Measures* & Outcomes \\
\hline
\end{tabular}

Im et al. (2019) Baseline and after 6 months of MMSE, CDR, neurological test battery
treatment

\section{Sandrini et al. (2016)}

Meinzer et al.

(2015)

Yun et al. (2016)

Fiori et al. (2017) During word retrieval: 1-10 presentations for each picture-word pair (T1-T10)

Westerberg et al. (2015)

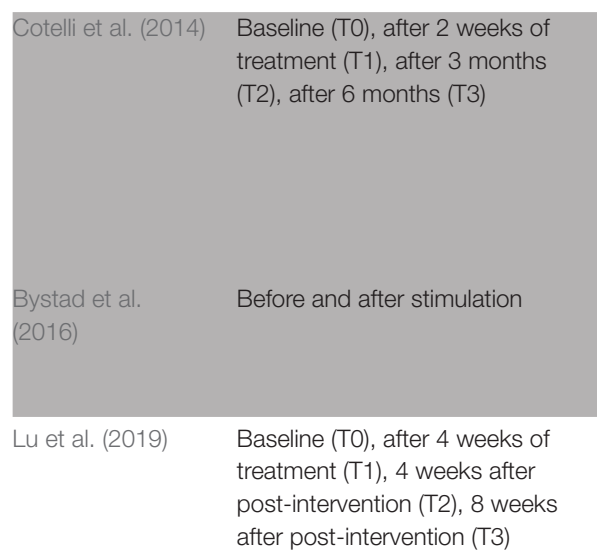

Before a 90-min nap and 30 min after

Learning performance, recall after $48 \mathrm{~h}$ and recall after 1 month

During stimulation (and fMRI)

Baseline and after 3-weeks of treatment

(digit span test, BNT, RCFT with immediate and delayed recall and recognition, clock drawing test, SVLT with immediate and delayed recall and recognition, contrasting program, Go-no go test, COWAT, Stroop word and color reading)

Learning and recall of a list of 20 words

Semantic word retrieval task

MMQ (MMQ-C, MMQ-A, MMQ-S)

Training, verification, and word retrieval of 20 pseudoword-picture associations (bisyllabic pseudowords)

Two declarative memory tests (word-pair recall, fast recognition test), 1 non-declarative test (object-priming test)

Face-name association task (FNAT), neuropsychological tests (picture naming task, BADA, Rivermead behavioral memory test, Rey auditory verbal learning test, Rey-Osterrieth test, complex figure copy, TMT A and B)

- MMSE and BNT scores significantly improved after active tDCS compared to sham

- Active tDCS resulted in consistent performance (at lower score levels) in contrasting program and Stroop word reading while scores decreased for sham

- Significant effect for recall after $48 \mathrm{~h}$ : Active tDCS group recalled significantly more words compared to sham

- No significant differences after 1 month

- tDCS significantly improved semantic word-retrieval performance in the patients to the level of controls

- MMQ-C significantly increased after active tDCS compared to sham

- Results for MMQ-A were similar to MMQ-C results but not significant between the active and sham groups

- No significant difference for MMQ-S between active tDCS and sham

- Bihemispheric: higher number of correct responses in the old group during T10 compared to T1 compared to unihemispheric and sham condition

- No differences between the three conditions in the young age group

- During T10 the young group was significantly more accurate than the old group for unihemispheric and sham; no significant difference in the bihemispehric condition

- Same results for vocal reaction times

- Recall improvement from pre-nap to post-nap was significantly larger for active so-tDCS compared to sham

- No significant fast recognition or object priming performance difference between active and sham so-tDCS after the nap (both increased significantly)

- FNAT: active or sham tDCS + memory training group showed significantly improved performances compared to active tDCS + motor training group at T1 and similar for T2, at T3 sham + memory training was still significant compared to the other two groups

- No differences in neuropsychological tests (except an improvement for both tDCS and sham + memory training at T3 in the TMT A score)

Primary: immediate and delayed recall and - CVLT-II: no significant differences between active and sham tDCS recognition of CVLT-II

Secondary: MMSE, clock drawing test, TMT $A$ and $B$

but a tendency toward higher improvement in CVLT-II recall after active tDCS

- No significant differences for secondary outcome measures

Primary: WM test (RT), ADAS-Cog

Secondary: CVFT, TMT, Chinese neuropsychiatric inventory (CNIP)

- ADAS-Cog: significant improvement for all groups at T1, but no difference between groups, tendency of falling back to baseline at T2 and T3 for all groups

- WM test: significant improvement for all groups until T3, tDCS+WMT showed highest WM capacity at T1 compared to other groups

- CVFT: tDCS-WMT showed a greater improvement in delayed recall compared to single-modality interventions; at T3 only the tDCS+WMT group showed significant enhancement on delayed recall performance over baseline

- tDCS-WMT group showed better performance of logical memory at 12 th week

- During sham younger adults produced significantly less errors than elderly

- Older subjects produced significantly less errors during active tDCS in comparison to sham

\begin{abstract}
Meinzer et al. During stimulation (and $\mathrm{fMRI}$ O O Overt semantic word generation task
Overt semantic word generation task
\end{abstract}


TABLE 3 | Continued

\begin{tabular}{|c|c|c|c|}
\hline \multirow[t]{2}{*}{ References } & \multicolumn{3}{|c|}{ Cognitive assessment (to evaluate tDCS effects on cognition) } \\
\hline & Timepoints & Measures* & Outcomes \\
\hline & & & $\begin{array}{l}\text { - Response times (RTs) were comparable between young and old } \\
\text { subjects during sham; no difference in RTs for elderly during } \\
\text { active tDCS compared to sham }\end{array}$ \\
\hline Khedr et al. (2014) & $\begin{array}{l}\text { Baseline (T0), after } 10 \text { days of } \\
\text { treatment (T1), after } 1 \text { month } \\
\text { (T2), after } 2 \text { months (T3) }\end{array}$ & $\begin{array}{l}\text { MMSE, WAIS-III (verbal comprehension, } \\
\text { arithmetic and digit span, perceptual } \\
\text { organization, processing speed) }\end{array}$ & $\begin{array}{l}\text { - MMSE: significant improvement in anodal and cathodal tDCS } \\
\text { compared to sham (increase of nearly } 2 \text { points at T1 and further } \\
\text { increase of } 2 \text { points at T2 and T3); anodal tDCS group showed } \\
\text { better improvement in orientation, registration, attention, and } \\
\text { naming object compared to cathodal tDCS } \\
\text { - WAIS-III: only cathodal and not anodal tDCS showed improved } \\
\text { performance IQ compared to sham }\end{array}$ \\
\hline Prehn et al. (2017) & $\begin{array}{l}\text { Immediate recall, delayed recall } \\
\text { after } 6 \mathrm{~h}, 1 \text { day later and } 1 \text { week } \\
\text { later }\end{array}$ & $\begin{array}{l}\text { Object-location learning task (LOCATO), } \\
\text { primary outcome: immediate recall, } \\
\text { secondary outcome: delayed recall }\end{array}$ & $\begin{array}{l}\text { - Significant effect of SSRI but not of stimulation on immediate } \\
\text { recall scores } \\
\text { - Young and old group profited most from atDCS+SSRI } \\
\text { - No significant effects on delayed recall }\end{array}$ \\
\hline $\begin{array}{l}\text { Manenti et al. } \\
(2017)\end{array}$ & $\begin{array}{l}\text { Baseline (after learning), free } \\
\text { recall and recognition } 48 \mathrm{~h} \text { and } \\
30 \text { days after learning (and tDCS) }\end{array}$ & $\begin{array}{l}\text { Learning, recall, and recognition of a list of } \\
20 \text { words }\end{array}$ & $\begin{array}{l}\text { - Significant difference on hit-false alarms score between atDCS } \\
\text { and sham at day } 30 \text {, anodal tDCS significantly improved memory } \\
\text { recognition on day } 30 \\
\text { - atDCS and sham group showed similar free recall performance } \\
\text { at day } 30\end{array}$ \\
\hline $\begin{array}{l}\text { Ferrucci et al. } \\
(2008)\end{array}$ & $\begin{array}{l}\text { Baseline and } 30 \text { min after } \\
\text { stimulation }\end{array}$ & $\begin{array}{l}\text { Word recognition task (WRT), visual } \\
\text { attention task }\end{array}$ & $\begin{array}{l}\text { - atDCS improved WRT accuracy, while ctDCS significantly } \\
\text { worsened it, sham left it unchanged; same results for DI (derived } \\
\text { by subtracting false positive from true positive responses) } \\
\text { - No significant differences in RTs in the visual attention task for } \\
\text { atDCS or ctDCS compared to sham }\end{array}$ \\
\hline $\begin{array}{l}\text { Boggio et al. } \\
(2012)\end{array}$ & $\begin{array}{l}\text { Baseline (T0), at the end of } \\
\text { treatment day } 5 \text { (T1), } 1 \text { week } \\
\text { later (T2), } 4 \text { weeks later (T3) }\end{array}$ & $\begin{array}{l}\text { MMSE, ADAS-Cog, visual recognition task } \\
\text { (VRT), visual attention task (VAT) }\end{array}$ & $\begin{array}{l}\text { - No significant effects for MMSE, ADAS-Cog, and VAT scores } \\
\text { between active and sham tDCS } \\
\text { - VRT: significant main effect for tDCS performance changes from } \\
\text { baseline: } 8.99 \% \text { after anodal and } 2.62 \% \text { after sham tDCS (for } \\
\text { T1, T2 and T3) }\end{array}$ \\
\hline $\begin{array}{l}\text { Cruz Gonzalez } \\
\text { et al. (2018) }\end{array}$ & $\begin{array}{l}\text { Screening, baseline (after CS } \\
\text { training), after sham+CS, after } \\
\text { tDCS+CS, post assessment } \\
\text { (after CS) }\end{array}$ & $\begin{array}{l}\text { Cognitive stimulation (planning ability and } \\
\text { divided attention, processing speed and } \\
\text { selective attention, short-term memory, } \\
\text { calculation and WM), CDR, MoCA }\end{array}$ & $\begin{array}{l}\text { - Enhanced cognitive performance in processing speed, selective } \\
\text { attention, WM activities, completion time in planning ability and } \\
\text { divided attention tasks for active tDCS compared to sham } \\
\text { - Variable CS outcomes but subjects did not show significantly } \\
\text { better outcomes in sham intervention compared to baseline CS }\end{array}$ \\
\hline
\end{tabular}

The only two studies that did not reveal significant effects are highlighted in gray. Cognitive measures: *MMSE, Minimal Mental State Examination; CDR, Clinical Dementia Rating (Morris, 1993); BNT, Boston Naming Test; RCFT, Rey Complex Figure Test; SVLT, Seoul Verbal Learning Test; COWAT, Controlled Oral Word Association Test; MMQ, Multifactorial Memory Questionnaire; BADA, Battery for the Analysis of the Aphasic Deficit; TMT, Trail Making Test; CVLT-II, California verbal learning test second edition; WM, Working Memory; ADAS-Cog,

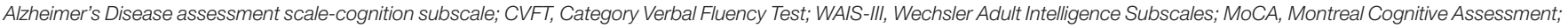
CS, Cognitive Stimulation.

show dominant activity in the left cortex, while cognitive decline upon aging seems to correlate with network alterations and "bihemispheric hyperactivity" (Goh, 2011; Antonenko et al., 2012; Meinzer et al., 2013). Targeting the LDLPFC may be one of the most effective possibilities as human cognition highly depends on cortical as well as subcortical networks involving the PFC (Frith and Dolan, 1996). Further, tDCS has very little mild adverse effects, which seem to depend on subjective sensation rather than stimulation parameters, so that a stimulation intensity of $2 \mathrm{~mA}$ may be chosen and sessions could last up to $30 \mathrm{~min}$ without risking significant side effects. Moreover, LT effects should be considered in future studies as they are advantageous for therapy considering the following aspects. Even though stimulators are now small and mobile, and the stimulations could be performed regularly by patients themselves after being trained by a specialist, at home tDCS is time consuming and requires certain skills as well as mobility. Independent application is particularly difficult for patients with cognitive disorders such as MCI or $\mathrm{AD}$ and a trained assistant such as a relative or a family doctor would be required to perform the stimulations properly. Additionally, in some cases repetitive stimulation may cause minor side effects as described above. Considering these limitations, treatment effects should outlast the time during stimulation, especially for application of tDCS in elderly people with cognitive impairment, and likewise persist in LT measurements.

In the field of NIBS research, stimulation interventions have so far mostly focused on group-based, general protocols. While standardization of study protocols may increase comparability which potentially facilitates translation of experimental studies into clinical applications, it can also be a major limitation 
of this methodology. Generalized stimulation practices might miss to fully consider the underlying mechanisms in the individual brain that guide the effective response to a given intervention. Therefore, NIBS protocols leveraging on the combination of stimulation approaches with electrical field modeling, neuroimaging and electrophysiology (Esmaeilpour et al., 2020) could advance the characterization of personalized response and prognostic biomarker discovery. This will result in a better understanding and reduction of variability of the response to stimulation. However, simulations of individual brains cannot be perfect due to uncertainties of the model parameters (e.g., conductivity) and EEG as well as fMRI methods both suffer from electric field artifacts. A recent study suggests the functional near-infrared spectroscopy (fNIRS) may be a better neuroimaging technique in order to study the hemodynamics response evoked by tDCS and consequently better dosing the stimulation (Arora et al., 2021). Indeed, a recent study investigated the feasibility of portable neuroimaging of cerebellar tDCS in conjunction with electroencephalography (EEG) to measure changes in the brain activation at the PFC and the sensorimotor cortex (SMC) in hemiparetic chronic stroke survivors. It was observed that there is a clear relationship between mean lobular electric field strength and oxy-hemoglobin concentrations/log10-transformed EEG band power. Nevertheless, future studies are needed to investigate and replicate these effects in a larger cohort and to clearly discriminate non-responders from responders. Afterall, an

\section{REFERENCES}

André, S., Heinrich, S., Kayser, F., Menzler, K., Kesselring, J., Khader, P. H., et al. (2016). At-home tDCS of the left dorsolateral prefrontal cortex improves visual short-term memory in mild vascular dementia. J. Neurol. Sci. 369, 185-190. doi: 10.1016/j.jns.2016.07.065

Antonenko, D., Grittner, U., Saturnino, G., Nierhaus, T., Thielscher, A., and Flöel, A. (2021). Inter-individual and age-dependent variability in simulated electric fields induced by conventional transcranial electrical stimulation. NeuroImage 224:117413. doi: 10.1016/j.neuroimage.2020.117413

Antonenko, D., Hayek, D., Netzband, J., Grittner, U., and Flöel, A. (2019). tDCS-induced episodic memory enhancement and its association with functional network coupling in older adults. Sci. Rep. 9:2273. doi: 10.1038/s41598-019-38630-7

Antonenko, D., Külzow, N., Sousa, A., Prehn, K., Grittner, U., and Flöel, A. (2018). Neuronal and behavioral effects of multi-day brain stimulation and memory training. Neurobiol. Aging 61, 245-254. doi: 10.1016/j.neurobiolaging.2017.09.017

Antonenko, D., Meinzer, M., Lindenberg, R., Witte, A. V., and Flöel, A. (2012). Grammar learning in older adults is linked to white matter microstructure and functional connectivity. NeuroImage. 62:1667-1674. doi: 10.1016/j.neuroimage.2012.05.074

Antonenko, D., Schubert, F., Bohm, F., Ittermann, B., Aydin, S., Hayek, D., et al. (2017). tDCS-induced modulation of GABA levels and restingstate functional connectivity in older adults. J. Neurosci. 37, 4065-4073. doi: 10.1523/JNEUROSCI.0079-17.2017

Arora, Y., Walia, P., Hayashibe, M., Muthalib, M., Chowdhury, S. R., Perrey, S., et al. (2021). Grey-box modeling and hypothesis testing of functional near-infrared spectroscopy-based cerebrovascular reactivity to anodal high-definition tDCS in healthy humans. In Review. 17:e1009386. doi: 10.1371/journal.pcbi.1009386 extended meta-analysis of the here reviewed studies and respective results could contribute to further specification and suggestions for future tDCS studies aiming to introduce novel treatment approaches to intervene with age-related cognitive deterioration as well as neurodegeneration.

\section{DATA AVAILABILITY STATEMENT}

The original contributions presented in the study are included in the article/supplementary material, further inquiries can be directed to the corresponding author.

\section{AUTHOR CONTRIBUTIONS}

AS performed database research and analysis, prepared figures and tables, and wrote the manuscript. LD reviewed and contributed to the manuscript. AA supervised the database research and analysis and reviewed the manuscript. All authors contributed to the article and approved the submitted version.

\section{FUNDING}

This study was supported by the Ministry of Lower Saxony for Science and Culture (76251-12-7/19; ZN 3456). We acknowledge support by the German Research Foundation and the Open Access Publication Funds of the Georg-August University Göttingen, Germany.
Ballard, C., Gauthier, S., Corbett, A., Brayne, C., Aarsland, D., and Jones, E. (2011). Alzheimer's disease. Lancet 377, 1019-1031. doi: 10.1016/S0140-6736(10)61349-9

Batsikadze, G., Moliadze, V., Paulus, W., Kuo, M.-F., and Nitsche, M. A. (2013). Partially non-linear stimulation intensity-dependent effects of direct current stimulation on motor cortex excitability in humans. J. Physiol. 591, 1987-2000. doi: 10.1113/jphysiol.2012.249730

Baudry, M. (2001). "Long-term potentiation (Hippocampus)," in International Encyclopedia of the Social and Behavioral Sciences, eds N. J. Smelser and B. Baltes (Amsterdam: Elsevier), 9081-9083,

Bear, M. F., and Malenka, R. C. (1994). Synaptic plasticity: LTP and LTD. Curr. Opin. Neurobiol. 4, 389-399. doi: 10.1016/0959-4388(94)90101-5

Berryhill, M. E., and Jones, K. T. (2012). tDCS selectively improves working memory in older adults with more education. Neurosci. Lett. 521, 148-151. doi: 10.1016/j.neulet.2012.05.074

Bindman, L. J., Lippold, O. C. J., and Redfearn, J. W. T. (1962). Long-lasting changes in the level of the electrical activity of the cerebral cortex produced by polarizing currents. Nature 196, 584-585. doi: 10.1038/196584a0

Boggio, P. S., Ferrucci, R., Mameli, F., Martins, D., Martins, O., Vergari, M., et al. (2012). Prolonged visual memory enhancement after direct current stimulation in Alzheimer's disease. Brain Stimul. 5, 223-230. doi: 10.1016/j.brs.2011.06.006

Boggio, P. S., Ferrucci, R., Rigonatti, S. P., Covre, P., Nitsche, M., PascualLeone, A., et al. (2006). Effects of transcranial direct current stimulation on working memory in patients with Parkinson's disease. J. Neurol. Sci. 249, 31-38. doi: 10.1016/j.jns.2006.05.062

Brambilla, M., Manenti, R., Ferrari, C., and Cotelli, M. (2015). Better together: left and right hemisphere engagement to reduce age-related memory loss. Behav. Brain Res. 293, 125-133. doi: 10.1016/j.bbr.2015.07.037

Braunewell, K.-H., and Manahan-Vaughan, D. (2001). Long-term depression: a cellular basis for learning? Rev. Neurosci. 12, 121-40. doi: 10.1515/REVNEURO.2001.12.2.121 
Brem, A.-K., Ran, K., and Pascual-Leone, A. (2013). Learning and memory. Handb. Clin. Neurol. 116, 693-737. doi: 10.1016/B978-0-444-53497-2.00055-3

Bystad, M., Grønli, O., Rasmussen, I. D., Gundersen, N., Nordvang, L., WangIversen, H., et al. (2016). Transcranial direct current stimulation as a memory enhancer in patients with Alzheimer's disease: a randomized, placebocontrolled trial. Alzheimers Res. Ther. 8:13. doi: 10.1186/s13195-016-0180-3

Bystad, M., Rasmussen, I. D., Grønli, O., and Aslaksen, P. M. (2017). Can 8 months of daily tDCS application slow the cognitive decline in Alzheimer's disease? a case study. Neurocase 23, 146-148. doi: 10.1080/13554794.2017.1325911

Cheng, C. P. W., Chan, S. S. M., Mak, A. D. P., Chan, W. C., Cheng, S. T., Shi, L., et al. (2015). Would transcranial direct current stimulation (tDCS) enhance the effects of working memory training in older adults with mild neurocognitive disorder due to Alzheimer's disease: study protocol for a randomized controlled trial. Trials 16:479. doi: 10.1186/s13063-015-0999-0

Coffman, B. A., Clark, V. P., and Parasuraman, R. (2014). Battery powered thought: Enhancement of attention, learning, and memory in healthy adults using transcranial direct current stimulation. NeuroImage 85, 895-908. doi: 10.1016/j.neuroimage.2013.07.083

Costa, V., Brighina, F., Piccoli, T., Realmuto, S., and Fierro, B. (2017). Anodal transcranial direct current stimulation over the right hemisphere improves auditory comprehension in a case of dementia. NeuroRehabilitation 41, 567-575. doi: 10.3233/NRE-162062

Cotelli, M., Manenti, R., Brambilla, M., Petesi, M., Rosini, S., Ferrari, C., et al. (2014). Anodal tDCS during face-name associations memory training in Alzheimer's patients. Front. Aging Neurosci. 6:38. doi: 10.3389/fnagi.2014.00038

Cruz Gonzalez, P., Fong, K. N. K., and Brown, T. (2018). The effects of transcranial direct current stimulation on the cognitive functions in older adults with mild cognitive impairment: a pilot study. Behav. Neurol. 2018, 1-14. doi: 10.1155/2018/5971385

Dickerson, B. C., and Eichenbaum, H. (2010). The episodic memory system: neurocircuitry and disorders. Neuropsychopharmacol. Off. Publ. Am. Coll. Neuropsychopharmacol. 35, 86-104. doi: 10.1038/npp.2009.126

Dickerson, B. C., Salat, D. H., Bates, J. F., Atiya, M., Killiany, R. J., Greve, D. N., et al. (2004). Medial temporal lobe function and structure in mild cognitive impairment. Ann. Neurol. 56, 27-35. doi: 10.1002/ana.20163

Eddy, C. M., Shapiro, K., Clouter, A., Hansen, P. C., and Rickards, H. E. (2017). Transcranial direct current stimulation can enhance working memory in Huntington's disease. Prog. Neuropsychopharmacol. Biol. Psychiatry 77, 75-82. doi: 10.1016/j.pnpbp.2017.04.002

Elder, G. J., Firbank, M. J., Kumar, H., Chatterjee, P., Chakraborty, T., Dutt, A., et al. (2016). Effects of transcranial direct current stimulation upon attention and visuoperceptual function in Lewy body dementia: a preliminary study. Int. Psychogeriatr. 28, 341-347. doi: 10.1017/S1041610215001180

Elder, G. J., and Taylor, J.-P. (2014). Transcranial magnetic stimulation and transcranial direct current stimulation: treatments for cognitive and neuropsychiatric symptoms in the neurodegenerative dementias? Alzheimers Res. Ther. 6:74. doi: 10.1186/s13195-014-0074-1

Esmaeilpour, Z., Shereen, A. D., Ghobadi-Azbari, P., Datta, A., Woods, A. J., Ironside, M., et al. (2020). Methodology for tDCS integration with fMRI. Hum. Brain Mapp. 41, 1950-1967. doi: 10.1002/hbm.24908

Ferrucci, R., Mameli, F., Guidi, I., Mrakic-Sposta, S., Vergari, M., Marceglia, S., et al. (2008). Transcranial direct current stimulation improves recognition memory in Alzheimer disease. Neurology 71, 493-498. doi: 10.1212/01.wnl.0000317060.43722.a3

Fiori, V., Nitsche, M., Iasevoli, L., Cucuzza, G., Caltagirone, C., and Marangolo, P. (2017). Differential effects of bihemispheric and unihemispheric transcranial direct current stimulation in young and elderly adults in verbal learning. Behav. Brain Res. 321, 170-175. doi: 10.1016/j.bbr.2016.12.044

Fjell, A. M., and Walhovd, K. B. (2010). Structural brain changes in aging: courses, causes and cognitive consequences. Rev. Neurosci. 21, 187-221. doi: 10.1515/revneuro.2010.21.3.187

Fletcher, P. C., and Henson, R. N. (2001). Frontal lobes and human memory: insights from functional neuroimaging. Brain J. Neurol. 124, 849-881. doi: $10.1093 /$ brain/124.5.849

Flöel, A. (2014). tDCS-enhanced motor and cognitive function in neurological diseases. NeuroImage 85 (Pt 3), 934-947. doi: 10.1016/j.neuroimage.2013.05.098
Frith, C., and Dolan, R. (1996). The role of the prefrontal cortex in higher cognitive functions. Brain Res. Cogn. Brain Res. 5, 175-181. doi: 10.1016/s0926-6410(96)00054-7

Gbadeyan, O., Steinhauser, M., Hunold, A., Martin, A. K., Haueisen, J., and Meinzer, M. (2019). Modulation of adaptive cognitive control by prefrontal high-definition transcranial direct current stimulation in older adults. J. Gerontol. Ser. B 74, 1174-1183. doi: 10.1093/geronb/ gbz048

Goh, J. O. S. (2011). Functional dedifferentiation and altered connectivity in older adults: neural accounts of cognitive aging. Aging Dis. 2, 30-48.

Gorman, A. L. (1966). Differential patterns of activation of the pyramidal system elicited by surface anodal and cathodal cortical stimulation. J. Neurophysiol. 29, 547-564. doi: 10.1152/jn.1966.29.4.547

Grossman, P., Alekseichuk, I., de Lara, G., Paneri, K., Kunz, P., Turi, Z., et al. (2018). transcranial Direct Current Stimulation Studies Open Database (tDCSOD). bioRxiv [Preprint]. doi: 10.1101/369215

Hsu, W.-Y., Ku, Y., Zanto, T. P., and Gazzaley, A. (2015). Effects of noninvasive brain stimulation on cognitive function in healthy aging and Alzheimer's disease: a systematic review and meta-analysis. Neurobiol. Aging 36, 2348-2359. doi: 10.1016/j.neurobiolaging.2015.04.016

Im, J. J., Jeong, H., Bikson, M., Woods, A. J., Unal, G., Oh, J. K., et al. (2019). Effects of 6-month at-home transcranial direct current stimulation on cognition and cerebral glucose metabolism in Alzheimer's disease. Brain Stimul. 12, 1222-1228. doi: 10.1016/j.brs.2019.06.003

Kabakov, A. Y., Muller, P. A., Pascual-Leone, A., Jensen, F. E., and Rotenberg, A. (2012). Contribution of axonal orientation to pathway-dependent modulation of excitatory transmission by direct current stimulation in isolated rat hippocampus. J. Neurophysiol. 107, 1881-1889. doi: 10.1152/jn.0071 5.2011

Keeser, D., Meindl, T., Bor, J., Palm, U., Pogarell, O., Mulert, C., et al. (2011). Prefrontal transcranial direct current stimulation changes connectivity of resting-state networks during fMRI. J. Neurosci. Off. J. Soc. Neurosci. 31, 15284-15293. doi: 10.1523/JNEUROSCI.0542-1 1.2011

Khedr, E. M., Gamal, N. F. E., El-Fetoh, N. A., Khalifa, H., Ahmed, E. M., Ali, A. M., et al. (2014). A double-blind randomized clinical trial on the efficacy of cortical direct current stimulation for the treatment of Alzheimer's disease. Front. Aging Neurosci. 6:275. doi: 10.3389/fnagi.2014.00275

Ladenbauer, J., Külzow, N., Passmann, S., Antonenko, D., Grittner, U., Tamm, S., et al. (2016). Brain stimulation during an afternoon nap boosts slow oscillatory activity and memory consolidation in older adults. NeuroImage 142, 311-323. doi: 10.1016/j.neuroimage.2016.06.057

Ladenbauer, J., Ladenbauer, J., Külzow, N., de Boor, R., Avramova, E., Grittner, U., et al. (2017). Promoting sleep oscillations and their functional coupling by transcranial stimulation enhances memory consolidation in mild cognitive impairment. J. Neurosci. 37, 7111-7124. doi: 10.1523/JNEUROSCI.0260-17.2017

Lefaucheur, J.-P., Antal, A., Ayache, S. S., Benninger, D. H., Brunelin, J., Cogiamanian, F., et al. (2017). Evidence-based guidelines on the therapeutic use of transcranial direct current stimulation (tDCS). Clin. Neurophysiol. 128, 56-92. doi: 10.1016/j.clinph.2016.10.087

Liebetanz, D., Nitsche, M. A., Tergau, F., and Paulus, W. (2002). Pharmacological approach to the mechanisms of transcranial DC-stimulation-induced aftereffects of human motor cortex excitability. Brain J. Neurol. 125, 2238-2247. doi: 10.1093/brain/awf238

Lu, H., Chan, S. S. M., Chan, W. C., Lin, C., Cheng, C. P. W., and Linda Chiu Wa, L. (2019). Randomized controlled trial of TDCS on cognition in 201 seniors with mild neurocognitive disorder. Ann. Clin. Transl. Neurol. 6, 1938-1948. doi: 10.1002/acn3.50823

Manenti, R., Brambilla, M., Petesi, M., Ferrari, C., and Cotelli, M. (2013). Enhancing verbal episodic memory in older and young subjects after non-invasive brain stimulation. Front. Aging Neurosci. 5:49. doi: $10.3389 /$ fnagi.2013.00049

Manenti, R., Sandrini, M., Gobbi, E., Binetti, G., and Cotelli, M. (2020). Effects of transcranial direct current stimulation on episodic memory in amnestic mild cognitive impairment: a pilot study. J. Gerontol. B. Psychol. Sci. Soc. Sci. 75, 1403-1413. doi: 10.1093/geronb/gbyl34 
Manenti, R., Sandrini, M., Gobbi, E., Cobelli, C., Brambilla, M., Binetti, G., et al. (2017). Strengthening of existing episodic memories through noninvasive stimulation of prefrontal cortex in older adults with subjective memory complaints. Front. Aging Neurosci. 9:401. doi: 10.3389/fnagi.201 7.00401

Martin, A. K., Meinzer, M., Lindenberg, R., Sieg, M. M., Nachtigall, L., and Flöel, A. (2017). Effects of transcranial direct current stimulation on neural networks in young and older adults. J. Cogn. Neurosci. 29, 1817-1828. doi: 10.1162/jocn_a_01166

Meinzer, M., Lindenberg, R., Antonenko, D., Flaisch, T., and Floel, A. (2013). Anodal transcranial direct current stimulation temporarily reverses ageassociated cognitive decline and functional brain activity changes. J. Neurosci. 33, 12470-12478. doi: 10.1523/JNEUROSCI.5743-12.2013

Meinzer, M., Lindenberg, R., Phan, M. T., Ulm, L., Volk, C., and Flöel, A. (2015). Transcranial direct current stimulation in mild cognitive impairment: behavioral effects and neural mechanisms. Alzheimers Dement. 11, 1032-1040. doi: 10.1016/j.jalz.2014.07.159

Mikkonen, M., Laakso, I., Tanaka, S., and Hirata, A. (2020). Cost of focality in TDCS: interindividual variability in electric fields. Brain Stimul. 13, 117-124. doi: 10.1016/j.brs.2019.09.017

Morris, J. C. (1993). The Clinical Dementia Rating (CDR): Current version and scoring rules. Neuro. 43:2412.2-2412-a. doi: 10.1212/WNL.43.11.2412-a

Murugaraja, V., Shivakumar, V., Sivakumar, P. T., Sinha, P., and Venkatasubramanian, G. (2017). Clinical utility and tolerability of transcranial direct current stimulation in mild cognitive impairment. Asian J. Psychiatry 30, 135-140. doi: 10.1016/j.ajp.2017.09.001

Nilsson, J., Lebedev, A. V., and Lövdén, M. (2015). No significant effect of prefrontal tDCS on working memory performance in older adults. Front. Aging Neurosci. 7:230. doi: 10.3389/fnagi.2015.00230

Nilsson, J., Lebedev, A. V., Rydström, A., and Lövdén, M. (2017). Directcurrent stimulation does little to improve the outcome of working memory training in older adults. Psychol. Sci. 28, 907-920. doi: 10.1177/0956797617 698139

Nitsche, M. A., Cohen, L. G., Wassermann, E. M., Priori, A., Lang, N., Antal, A., et al. (2008). Transcranial direct current stimulation: state of the art 2008. Brain Stimul. 1, 206-223. doi: 10.1016/j.brs.2008.06.004

Nitsche, M. A., Fricke, K., Henschke, U., Schlitterlau, A., Liebetanz, D., Lang, N., et al. (2003a). Pharmacological modulation of cortical excitability shifts induced by transcranial direct current stimulation in humans. J. Physiol. 553, 293-301. doi: 10.1113/jphysiol.2003.049916

Nitsche, M. A., Jaussi, W., Liebetanz, D., Lang, N., Tergau, F., and Paulus, W. (2004). Consolidation of human motor cortical neuroplasticity by D-cycloserine. Neuropsychopharmacol. Off. Publ. Am. Coll. Neuropsychopharmacol. 29, 1573-1578. doi: 10.1038/sj.npp.1300517

Nitsche, M. A., Liebetanz, D., Antal, A., Lang, N., Tergau, F., and Paulus, W. (2003b). Modulation of cortical excitability by weak direct current stimulationtechnical, safety and functional aspects. Suppl. Clin. Neurophysiol. 56, 255-276. doi: 10.1016/s1567-424x(09)70230-2

Nitsche, M. A., Nitsche, M. S., Klein, C. C., Tergau, F., Rothwell, J. C., and Paulus, W. (2003c). Level of action of cathodal DC polarisation induced inhibition of the human motor cortex. Clin. Neurophysiol. Off. J. Int. Fed. Clin. Neurophysiol. 114, 600-604. doi: 10.1016/s1388-2457(02)00412-1

Nitsche, M. A., and Paulus, W. (2000). Excitability changes induced in the human motor cortex by weak transcranial direct current stimulation. J. Physiol. 527, 633-639. doi: 10.1111/j.1469-7793.2000.t01-1-00633.x

Nitsche, M. A., and Paulus, W. (2001). Sustained excitability elefations induced by transcranial DC motor cortex stimulation in humans. Neurology 57, 1899-1901. doi: 10.1212/WNL.57.10.1899

Opitz, A., Paulus, W., Will, S., Antunes, A., and Thielscher, A. (2015). Determinants of the electric field during transcranial direct current stimulation. NeuroImage 109, 140-150. doi: 10.1016/j.neuroimage.2015.01.033

Page, M. J., McKenzie, J. E., Bossuyt, P. M., Boutron, I., Hoffmann, T. C., Mulrow, C. D., et al. (2021). The PRISMA 2020 statement: an updated guideline for reporting systematic reviews. BMJ 372:n71. doi: 10.1136/bmj.n71

Paßmann, S., Külzow, N., Ladenbauer, J., Antonenko, D., Grittner, U., Tamm, S., et al. (2016). Boosting Slow Oscillatory Activity Using tDCS during Early Nocturnal Slow Wave Sleep Does Not Improve Memory Consolidation in Healthy Older Adults. Brain Stimulat. 9, 730-739. doi: 10.1016/j.brs.2016.04.016
Penolazzi, B., Bergamaschi, S., Pastore, M., Villani, D., Sartori, G., and Mondini, S (2015). Transcranial direct current stimulation and cognitive training in the rehabilitation of Alzheimer disease: A case study. Neuropsychol. Rehabil. 25, 799-817. doi: 10.1080/09602011.2014.977301

Petersen, R. C., Lopez, O., Armstrong, M. J., Getchius, T. S. D., Ganguli, M., Gloss, D., et al. (2018). Practice guideline update summary: Mild cognitive impairment: Report of the Guideline Development, Dissemination, and Implementation Subcommittee of the American Academy of Neurology. Neurology 90, 126-135. doi: 10.1212/WNL.0000000000004826

Petersen, R. C., and Negash, S. (2008). Mild cognitive impairment: an overview. CNS Spectr. 13, 45-53. doi: 10.1017/s1092852900016151

Polanía, R., Nitsche, M. A., and Paulus, W. (2011a). Modulating functional connectivity patterns and topological functional organization of the human brain with transcranial direct current stimulation. Hum. Brain Mapp. 32, 1236-1249. doi: 10.1002/hbm.21104

Polanía, R., Paulus, W., Antal, A., and Nitsche, M. A. (2011b). Introducing graph theory to track for neuroplastic alterations in the resting human brain: a transcranial direct current stimulation study. NeuroImage 54, 2287-2296. doi: 10.1016/j.neuroimage.2010.09.085

Polanía, R., Paulus, W., and Nitsche, M. A. (2012). Modulating cortico-striatal and thalamo-cortical functional connectivity with transcranial direct current stimulation. Hum. Brain Mapp. 33, 2499-2508. doi: 10.1002/hbm.21380

Prehn, K., and Flöel, A. (2015). Potentials and limits to enhance cognitive functions in healthy and pathological aging by tDCS. Front. Cell. Neurosci. 9. doi: 10.3389/fncel.2015.00355

Prehn, K., Stengl, H., Grittner, U., Kosiolek, R., Ölschläger, A., Weidemann, A., et al. (2017). Effects of anodal transcranial direct current stimulation and serotonergic enhancement on memory performance in young and older adults. Neuropsychopharmacology 42, 551-561. doi: 10.1038/npp.2016.170

Priori, A., Berardelli, A., Rona, S., Accornero, N., and Manfredi, M. (1998). Polarization of the human motor cortex through the scalp. Neuroreport 9, 2257-2260. doi: 10.1097/00001756-199807130-00020

Purpura, D. P., and McMurtry, J. G. (1965). Intracellular activities and evoked potential changes during polarization of motor cortex. J. Neurophysiol. 28, 166-185. doi: 10.1152/jn.1965.28.1.166

Rahman, A., Reato, D., Arlotti, M., Gasca, F., Datta, A., Parra, L. C., et al. (2013). Cellular effects of acute direct current stimulation: somatic and synaptic terminal effects. J. Physiol. 591, 2563-2578. doi: 10.1113/jphysiol.2012.247171

Reitz, C., and Mayeux, R. (2014). Alzheimer disease: epidemiology, diagnostic criteria, risk factors and biomarkers. Biochem. Pharmacol. 88, 640-651. doi: 10.1016/j.bcp.2013.12.024

Rönnlund, M., Nyberg, L., Bäckman, L., and Nilsson, L.-G. (2005). Stability, growth, and decline in adult life span development of declarative memory: cross-sectional and longitudinal data from a population-based study. Psychol. Aging 20, 3-18. doi: 10.1037/0882-7974.20.1.3

Ross, L. A., McCoy, D., Coslett, H. B., Olson, I. R., and Wolk, D. A. (2011). Improved proper name recall in aging after electrical stimulation of the anterior temporal lobes. Front. Aging Neurosci. 3:16. doi: 10.3389/fnagi.2011.00016

Sandrini, M., Manenti, R., Brambilla, M., Cobelli, C., Cohen, L. G., and Cotelli, M. (2016). Older adults get episodic memory boosting from noninvasive stimulation of prefrontal cortex during learning. Neurobiol. Aging 39, 210-216. doi: 10.1016/j.neurobiolaging.2015.12.010

Shin, Y.-I., Foerster, Á., and Nitsche, M. A. (2015). Transcranial direct current stimulation (tDCS) - application in neuropsychology. Neuropsychologia 69, 154-175. doi: 10.1016/j.neuropsychologia.2015.02.002

Smith, A. D. (2002). Imaging the progression of Alzheimer pathology through the brain. Proc. Natl. Acad. Sci. U.S.A. 99, 4135-4137. doi: 10.1073/pnas.082107399

Stagg, C. J., Best, J. G., Stephenson, M. C., O’Shea, J., Wylezinska, M., Kincses, Z. T., et al. (2009). Polarity-sensitive modulation of cortical neurotransmitters by transcranial stimulation. J. Neurosci. 29, 5202-5206. doi: 10.1523/JNEUROSCI.4432-08.2009

Stephens, J. A., and Berryhill, M. E. (2016). Older adults improve on everyday tasks after working memory training and neurostimulation. Brain Stimulat. 9, 553-559. doi: 10.1016/j.brs.2016.04.001

Thams, F., Kuzmina, A., Backhaus, M., Li, S.-C., Grittner, U., Antonenko, D., et al. (2020). Cognitive training and brain stimulation in prodromal Alzheimer's disease (AD-Stim) - study protocol for a double-blind randomized controlled phase IIb (monocenter) trial. Alzheimers Res. Ther. 12:142. doi: 10.1186/s13195-020-00692-5 
United Nations (2019). Growing at a Slower Pace, World Population Is Expected to Reach 9.7 Billion in 2050 and Could Peak at Nearly 11 Billion Around 2100|UN DESA | United Nations Department of Economic and Social Affairs. Available online at: https://www.un.org/development/desa/en/news/population/worldpopulation-prospects-2019.html (accessed March 2, 2021).

Westerberg, C. E., Florczak, S. M., Weintraub, S., Mesulam, M.-M., Marshall, L., Zee, P. C., et al. (2015). Memory improvement via slow-oscillatory stimulation during sleep in older adults. Neurobiol. Aging 36, 2577-2586. doi: 10.1016/j.neurobiolaging.2015.05.014

Woods, A. J., Cohen, R., Marsiske, M., Alexander, G. E., Czaja, S. J., and Wu, S. (2018). Augmenting cognitive training in older adults (The ACT Study): design and Methods of a Phase III tDCS and cognitive training trial. Contemp. Clin. Trials 65, 19-32. doi: 10.1016/j.cct.2017.11.017

World Health Organization (2020). Dementia. Available online at: https://www. who.int/news-room/fact-sheets/detail/dementia (accessed March 2, 2021).

Yun, K., Song, I.-U., and Chung, Y.-A. (2016). Changes in cerebral glucose metabolism after 3 weeks of noninvasive electrical stimulation of mild cognitive impairment patients. Alzheimers Res. Ther. 8:49. doi: 10.1186/s13195-016-0218-6
Conflict of Interest: The authors declare that the research was conducted in the absence of any commercial or financial relationships that could be construed as a potential conflict of interest.

Publisher's Note: All claims expressed in this article are solely those of the authors and do not necessarily represent those of their affiliated organizations, or those of the publisher, the editors and the reviewers. Any product that may be evaluated in this article, or claim that may be made by its manufacturer, is not guaranteed or endorsed by the publisher.

Copyright (c) 2021 Siegert, Diedrich and Antal. This is an open-access article distributed under the terms of the Creative Commons Attribution License (CC BY). The use, distribution or reproduction in other forums is permitted, provided the original author(s) and the copyright owner(s) are credited and that the original publication in this journal is cited, in accordance with accepted academic practice. No use, distribution or reproduction is permitted which does not comply with these terms. 